\title{
خيار الاقتصاد الأخضر بين فرص النجاح ومؤشرات الفشل في المنطقة العربية
}

The green economy option between success opportunities and failure indicators in the Arab region

تاريخ الاستلام : 2019/04/15؛ تاريخ القبول : 2019/04/22

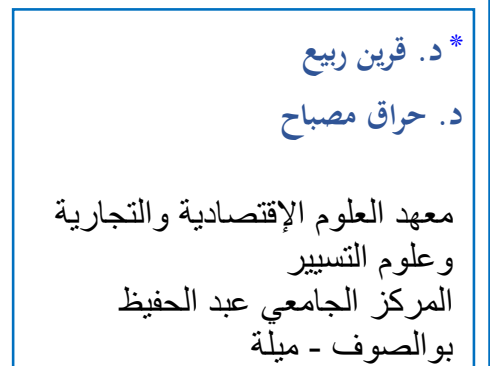

\section{Abstract}

The path to the green economy is a major challenge at the regional and global levels, and Arab countries are now looking for a turning point in their development process, in which the green economy is one of the most way of adopting a new economic model. In this research paper we extract several successful lessons from Arab countries in the context of the green economy, and in order to achieve our goal we use a descriptive and analytical approach, and this to extract results and formulate a new model development policies and increase the opportunities for success in their application.

The success of green economy initiatives requires the establishment of effective partnerships between the public and private sectors, environmental, economic and financial coordination requires developing a new economic model for the transition to a green economy, creating new jobs, eradicate poverty and move towards global and sustainable development.

Keywords: green economy, indicators of green economy, sustainable development, development, global experiences in the green economy.

\section{Résumé}

Le chemin qui mène à l'économie verte est un défi important aux niveaux régional et mondial, et les pays arabes sont aujourd'hui à la recherche d'un tournant dans leur processus de développement, dans lequel l'économie verte est l'un moyen d'adopter un nouveau modèle économique. Dans ce document de recherche on a extraire plusieurs lessons réussies des pays arabes dans le cadre de l'économie verte, et afin d'atteindre notre objectif on utilise une approche descriptive et analytique, et cela pour extraire des résultats et bien formuler de nouveau modèle des politiques de développement et augmenter les opportunités de succès dans leur application.

Le succès des initiatives d'économie verte exige la mise en place de partenariats efficaces entre les secteurs public et privé, une coordination dans les domaines environnemental, économique et financier nécessite de développer un nouveau modèle économique pour la transition vers une économie verte, de créer de nouveaux emplois, d'éliminer la pauvreté et de progresser vers un développement global et durable.

Mots clés: économie verte, indicateurs de l'économie verte, développement durable, développement, expériences mondiaux dans l'économie verte.

* Corresponding author, e-mail: cmp25a@yahoo.fr 
لا شك أن خيبة الأمل في نظامنا الاقتصادي السائد قد ساهمت في تلك القوة التي

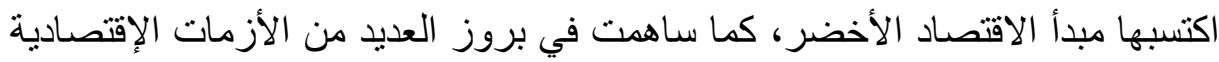

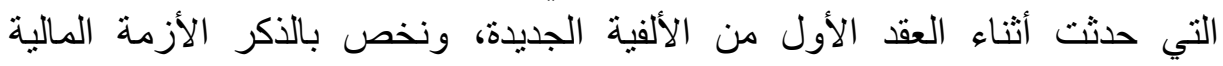

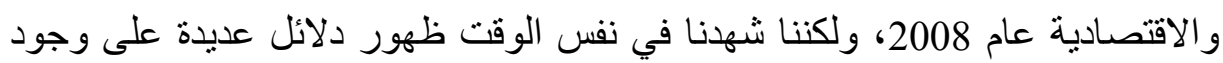

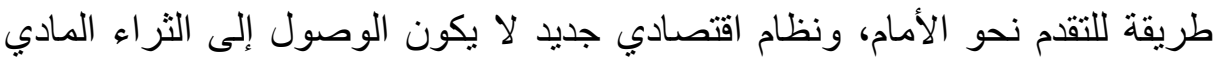

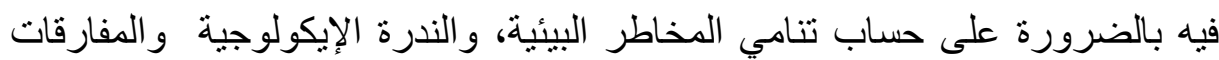

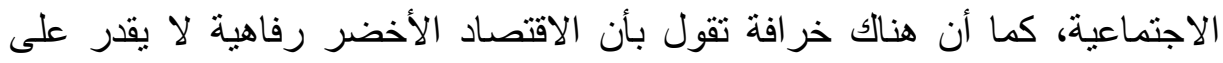

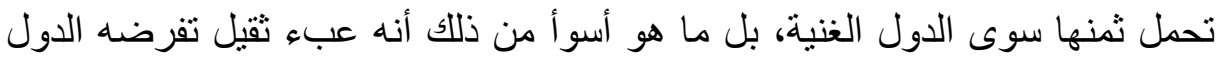

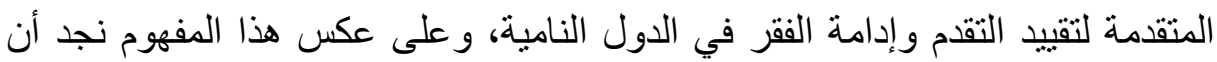

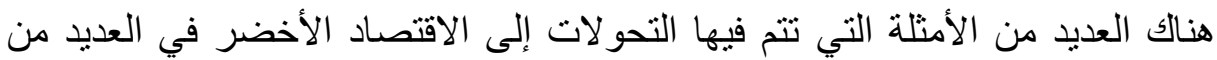
القطاعات في العالم النامي و التي تستحق المحاكاة.

إثكالية الدراسة: تتمحور إثكالية دراستنا حول:

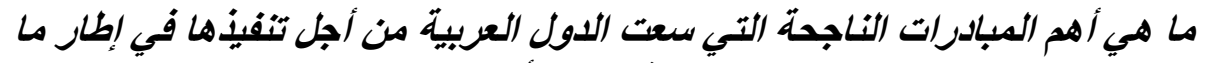
يعرف بالاقتصاد الأخضر?

التساؤلات الفرعية: للإجابة عن الإشكالية الرئيسية ارتأينا طرح الأبساؤلائلات الفرعية - ما هو الإطار النظري الذي يحدد ماهية الاقتصاد الأخضر؟

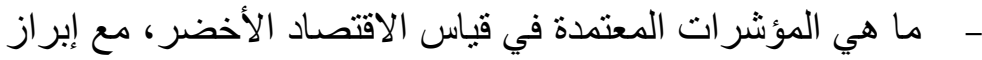

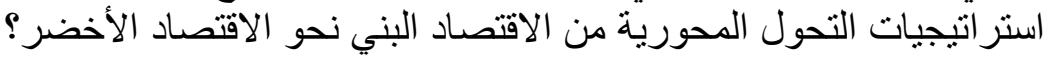
- ما هي أهم المشاريع المطبقة من قبل الدول العربية الناجحة في ما يخص

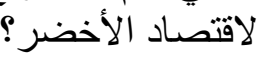

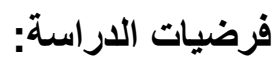

- الاقتصاد الأخضر من المفاهيم والمصطلحات الحديثة التي تعزز نهج التنمية

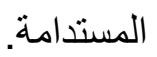

- - هنالك مؤشر ات أساسية كمية ونوعية يمكن الإستعانة بها لقياس التقدم المحرز

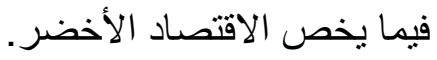

- - باثرت العديد من الدول العربية في تطبيق المشاريع المتعلقة بالاقتصاد

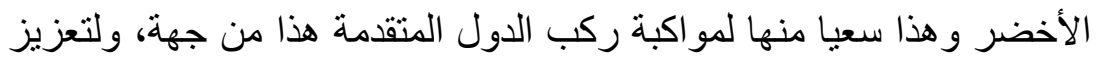

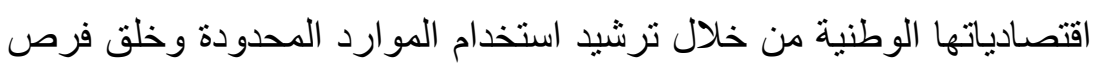
استثمار و عمل جديدة. أهداف الدراسة: تتدرج أهم اهداف الدراسة في: - - تسليط الضوء على المفاهيم الجديدة للاقتصاد الأخضر و الصناعة الهن الخضر اء. 


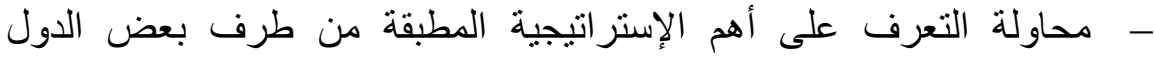

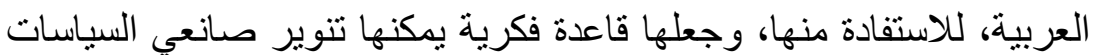
العامة وخاصة العربية منها.

منهج الدراسة: سيتم اعتماد المنهج الوصفي التحليلي في دراستنا، لتوافقه مع وصف

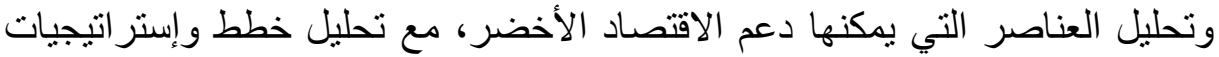

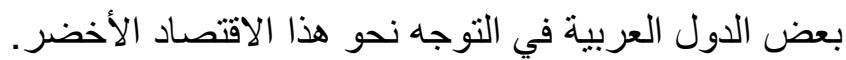

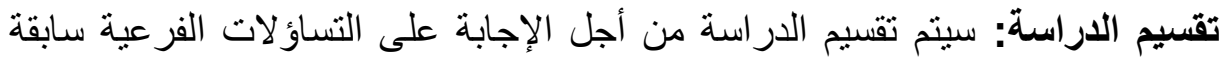

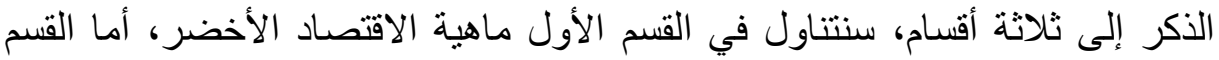
الثاني فسيتم تخصيصه لدراسة مؤشر ات، متطلبات وتحديات و الحلول من أجل التحول

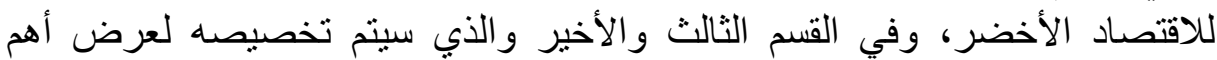
مبادر ات الدول العالمية والعربية فيما يخص الاقتصاد الأخضر.

أولا: ماهية الاقتصاد الأخضر: سنتناول في هذا العنصر كلا من مفهوم الاقتصاد الأخضر وجذانور الأفره التاريخية، مع تبيان أهم أهداف هذا الاقتصاد.

\section{1- 1 مفهوم الاقتصاد الأخضر:}

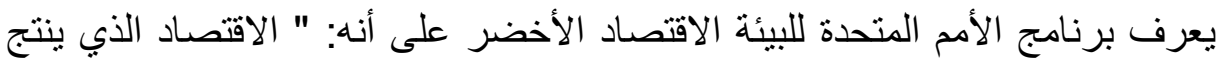

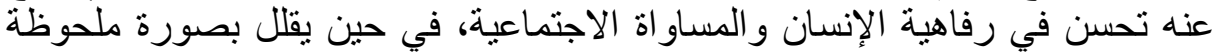

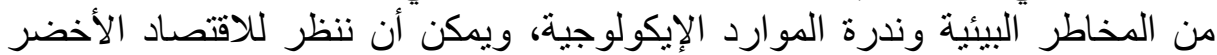

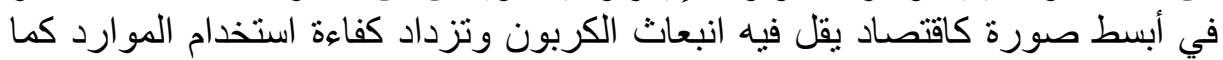

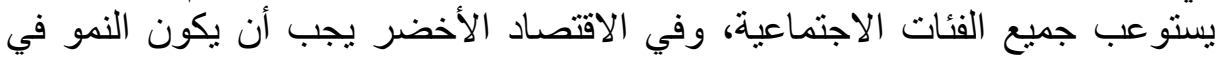

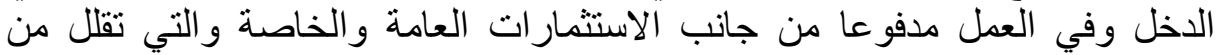

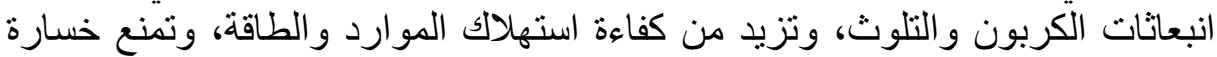

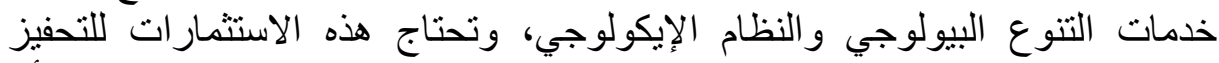

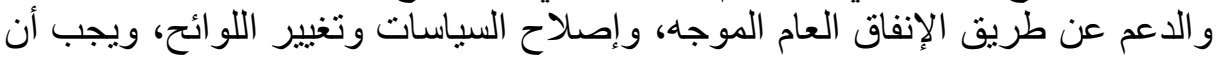

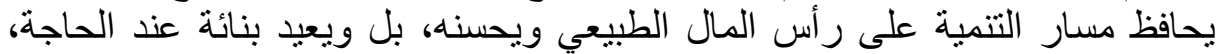

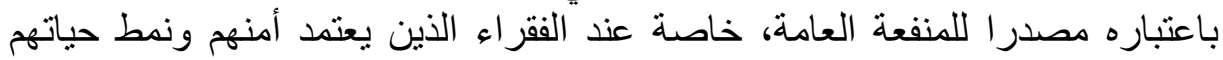

على الطبيعة". (1)

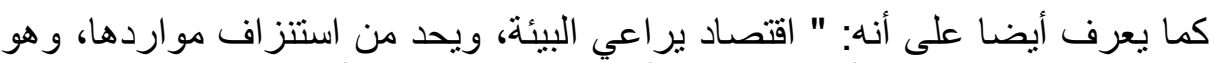

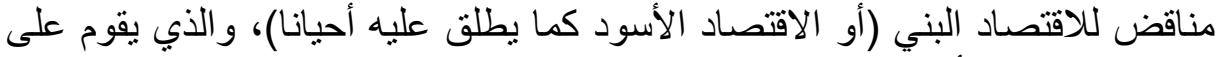

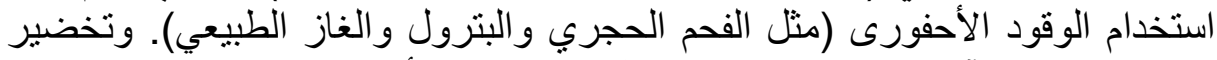

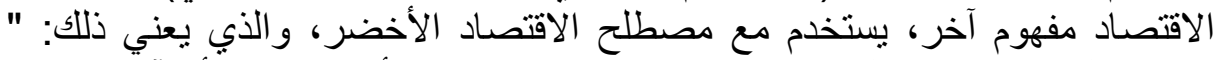

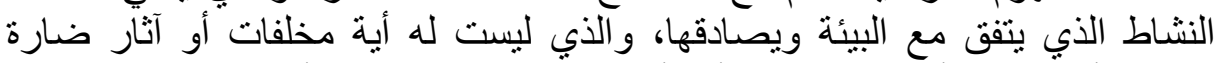
بالبيئة، أو على الأقل لا يضيف أية أعباء جديدة على البيئة أو يزيد درجة تلوثها

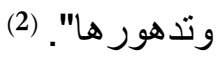

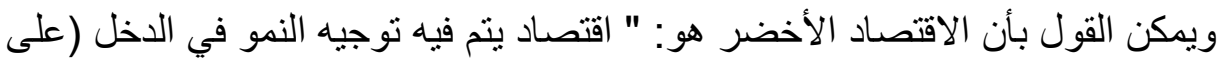

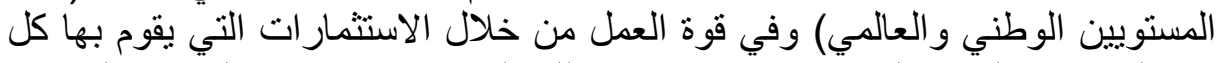

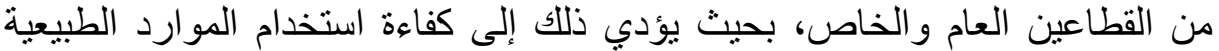
و البشرية، وتخفيض الانبعاثات و الملوثات الضارة بالبيئة، والحد من النفايات، 


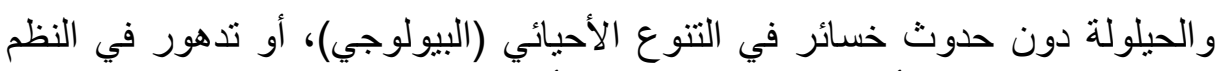

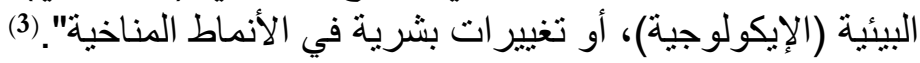

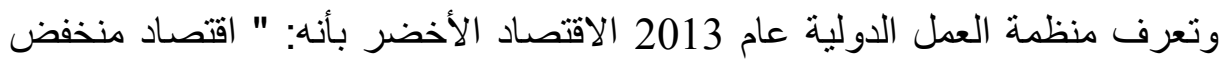

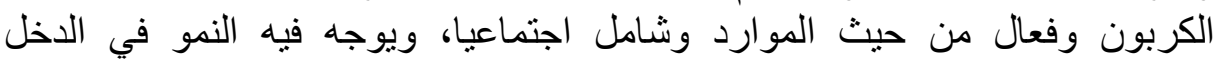
و العمالة بو اسطة استثمار ات من القطاعين العام و الخاص تفضي إلى ونى تخفيض إنى انبعانات

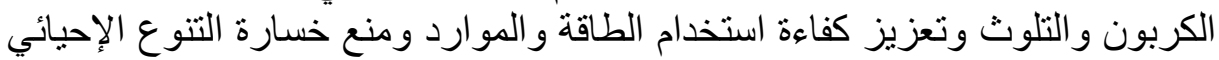

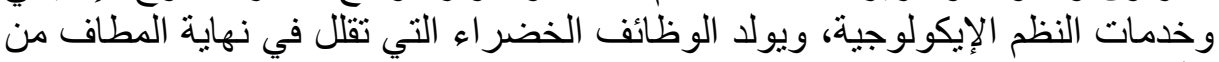

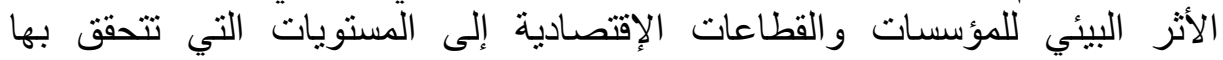

الاستدامة". (4)

يعتبر الاقتصاد الأخضر: " اقتصادا منخفض الكربون الأناج أبي أنه ذات كفاءة وهو نظيف

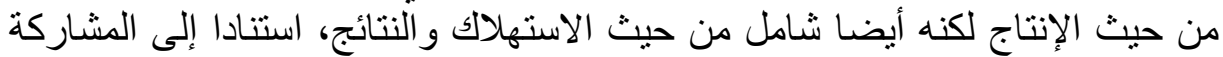

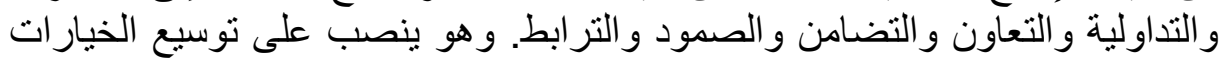

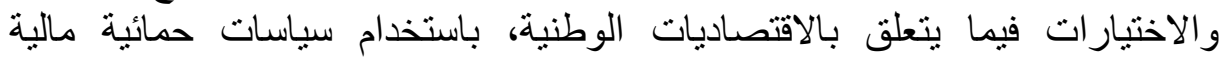
واجتماعية هادفة ومناسبة، وتدعمه مؤسسات قوية موالاتية موجهة بشكل محدد نحو الحفاظ

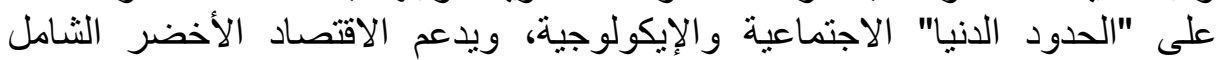

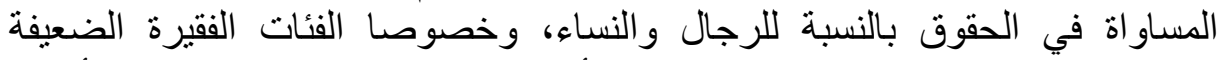

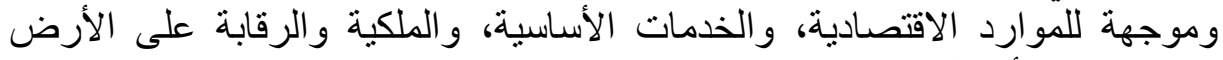

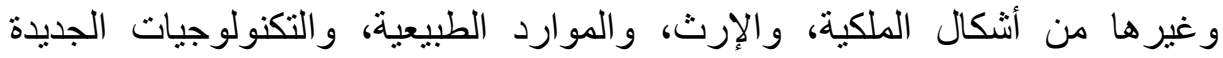

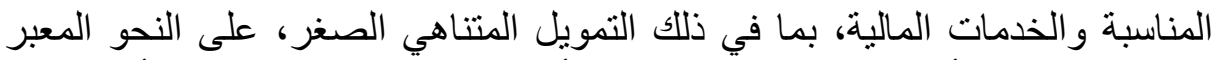

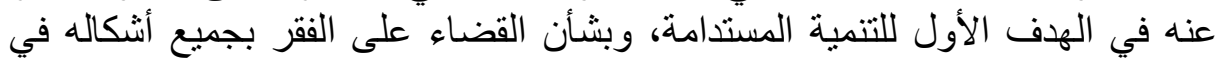

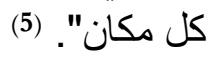

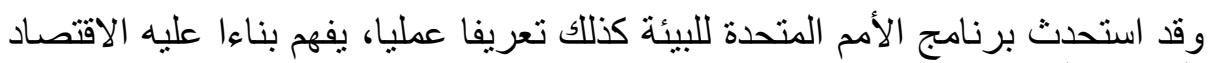

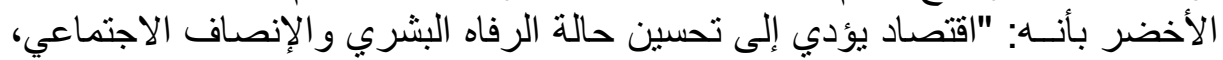

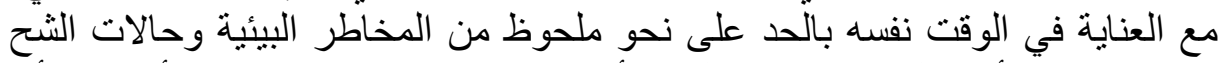

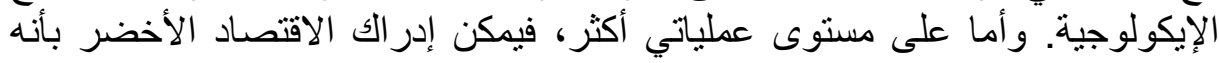

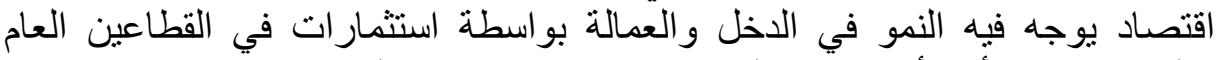

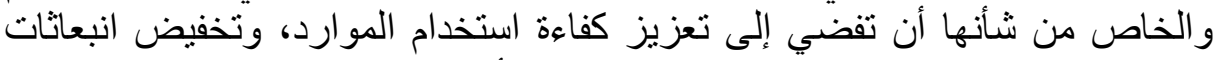

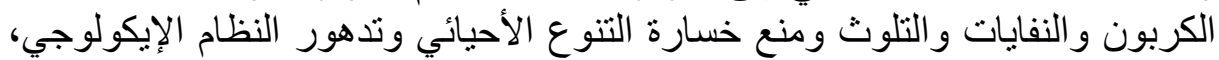

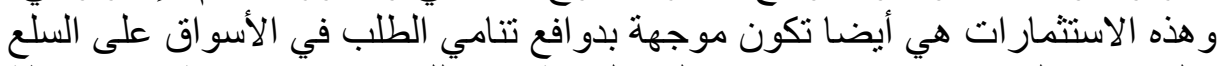

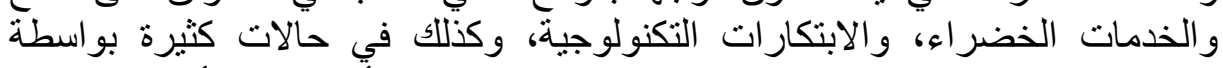

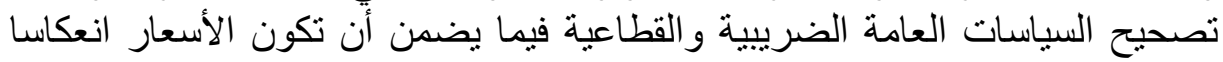

ملائما للتكاليف البيئية".

من خلال التعاريف السابقة يمكن استخلاص أن الاقتصاد الأخضر : - - هو اقتصاد منخفض الكربون؛

- مخفف من حدة التلوث البيئي؛

- - يؤدي إلى التنمية البشرية، من حيث تحسين رفاهية الفرد و القضاء على الفقر؛ - - يحافظ على حق الأجيال اللاحقة من خلال تتمية اقتصادية مستدامة؛ - - بساهم في التتوع البيولوجي. 
2- الجذور التاريخية لمفهوم الاقتصاد الأخضر:

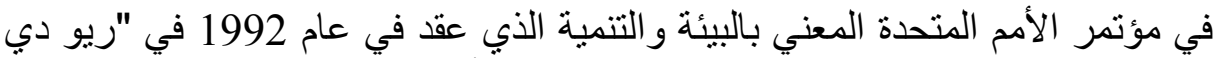

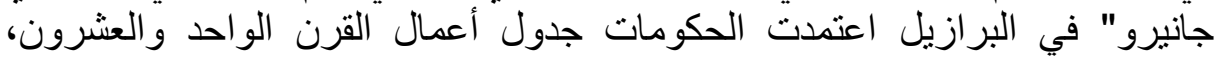

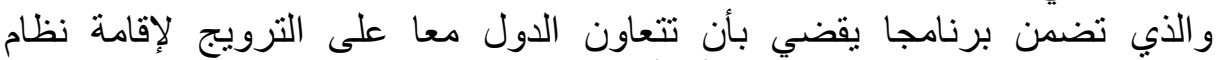

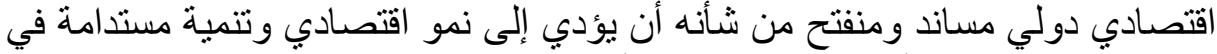

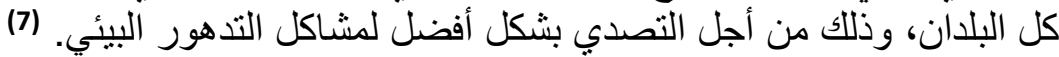

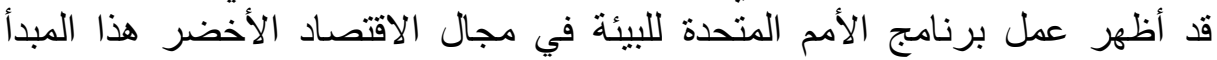
بصورة جلية في عام 2008، وبصفة خاصة من خلال الاتفاقية البيئية العالمية الجديدة الإنة الإنة

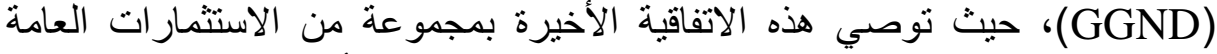
والسياسات التكميلية والإصلاحات السعرية التي تهدف لبدأ الإنتقال إلى الإنى الإتصاد التصاد

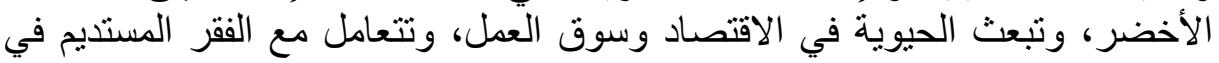
نفس الوقت، وكان مقترح الاتفاقية البيئية الخضر اءث العالمية الجاء الجديدة كرد فعل سياسي

مناسب للأزمة الإقتصادية و المالية لعام 2008.

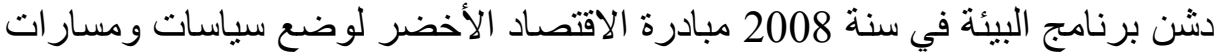

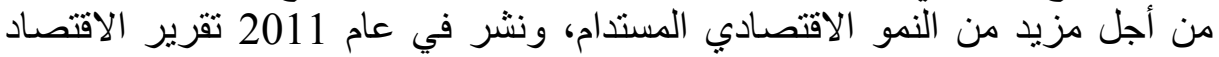

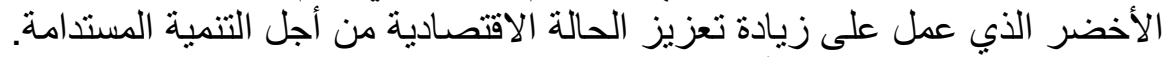

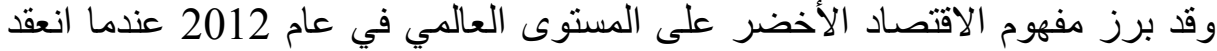

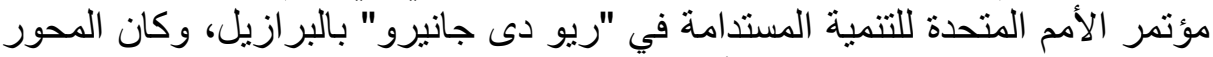

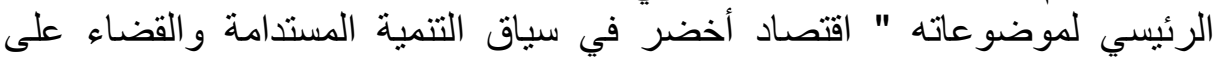
الفقر". (9) - (9)

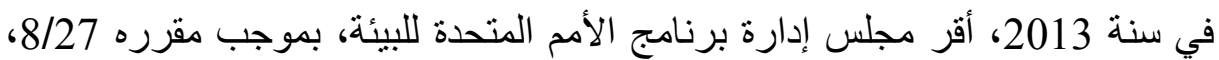
بشأن الاقتصاد الأخضر في سياق التنمية المستدامة والقضاء على الفئ الفقر، أنه توجد هناك مسار ات مختلفة لتحقيق التنمية المستدامة.

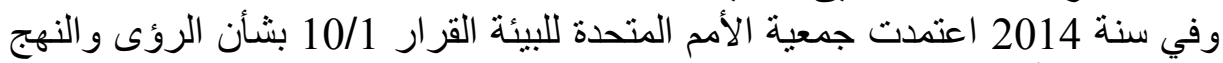

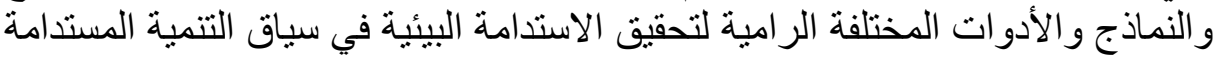

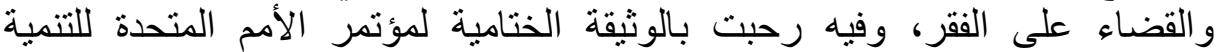
المستدامة " المستقبل الذي نصبو إليه".

\section{هداف الاقتصاد الأخضر:}

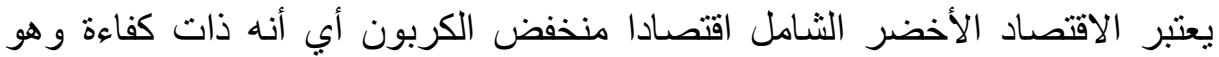

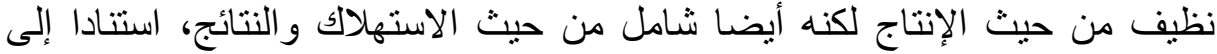

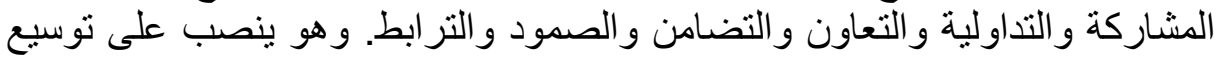

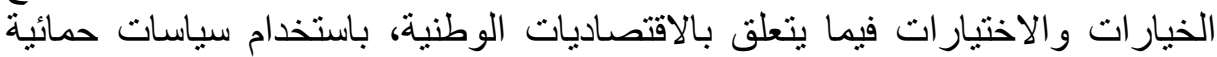

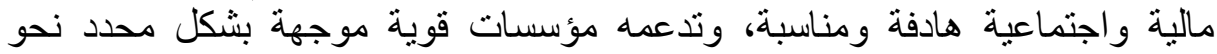
الحفاظ على "الحدود الانيا" الاجتماعية والإيكولوجية. ولتية ويدعم الاقتصاد الأخضر

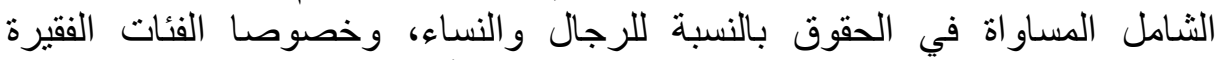

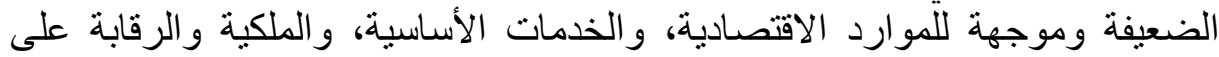

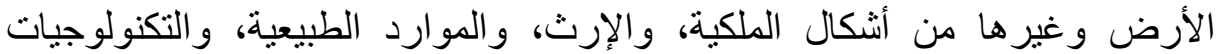

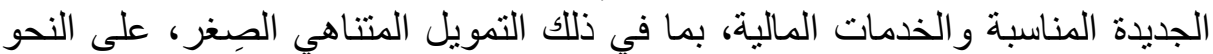


المعبر عنه في الهدف الأول للتنمية المستدامة، وبشأن القضاء على الفقر بجميع أشكاله

في كل مكان. (10)

ومن أهم الأهداف الإستر اتيجية للاقتصاد الأخضر كونه: (10) أ- الاقتصاد الأخضر يعزز السعي إلى التخفيف من حدة الفقر:

إن الإستراتيجية التي تعنى بالاقتصاد الأخضر يمكن أن تسهم في تحقيق النمو

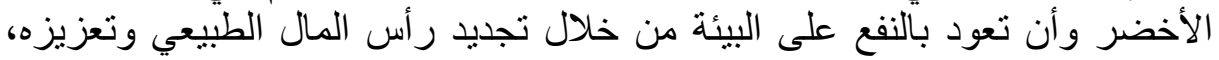

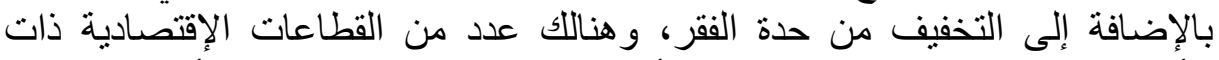

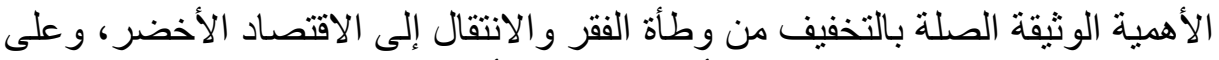

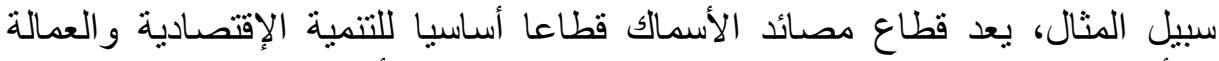

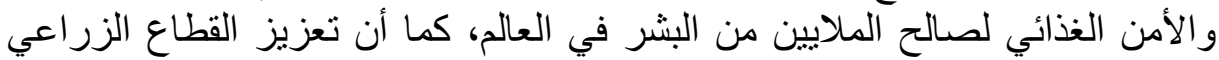

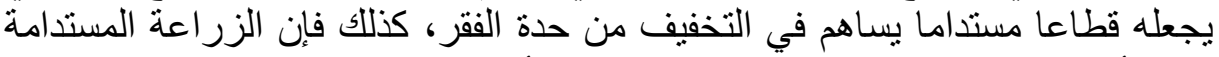

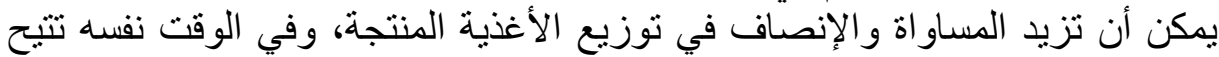

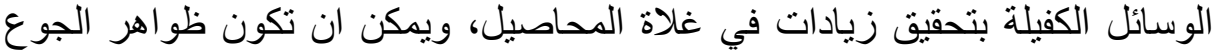

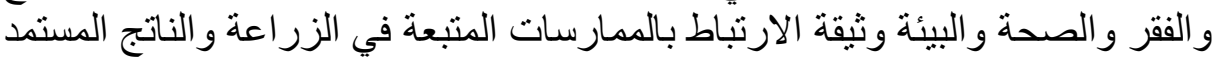

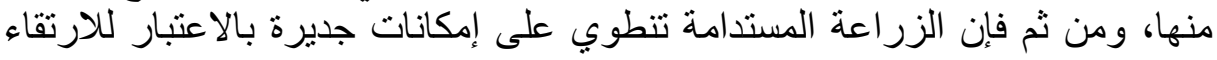
بنو عية الحياة في المجتمعات المحلية المنية الريفية. ب- الاقتصاد الأخضر ينطوي على إمكانات لاستحداث فرضة الرض عمل إضافية:

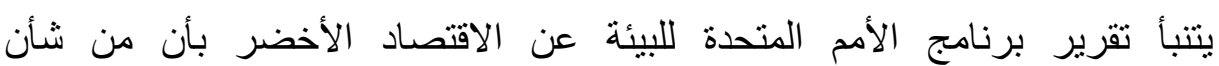

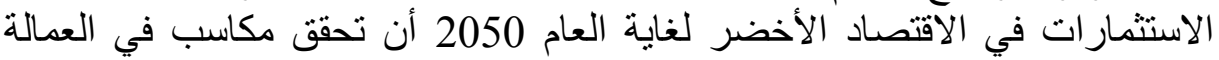

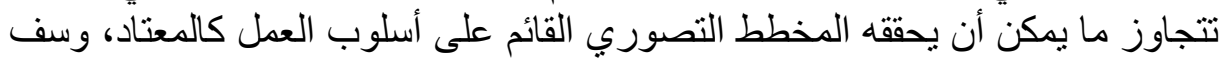

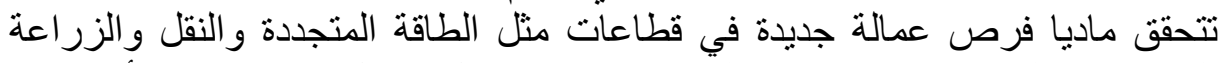

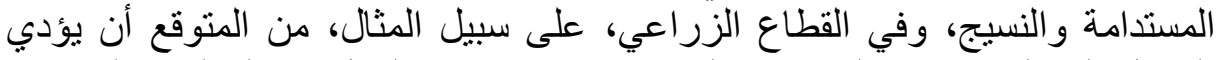

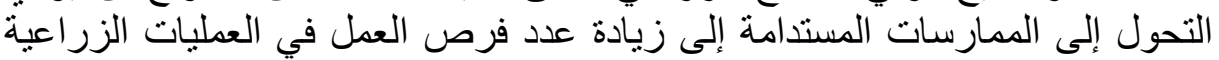

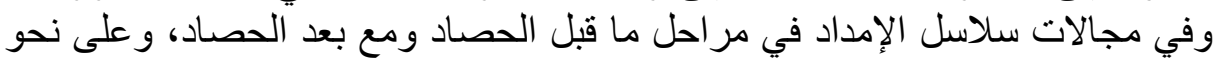

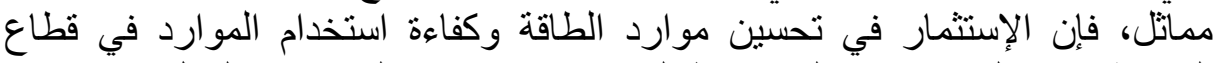

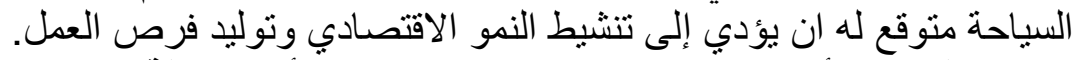

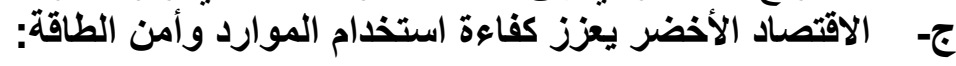

إن زيادة المعروض من الطاقة عن طريق المصادر المتجددة يقلل من مخاطر أسعار

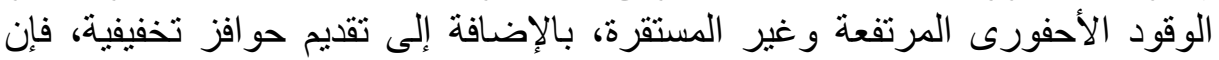

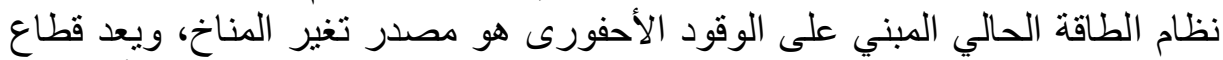

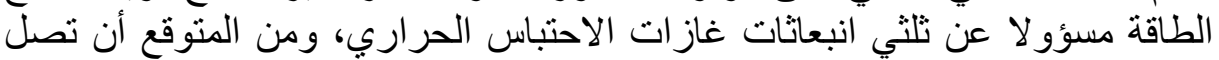

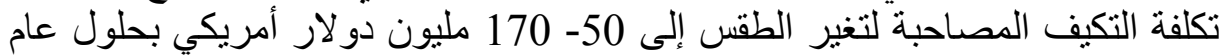

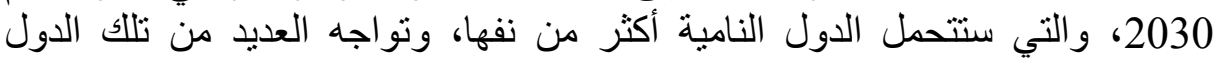

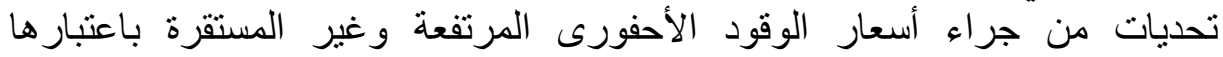

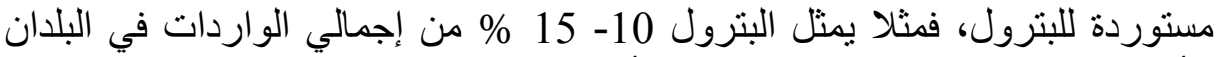

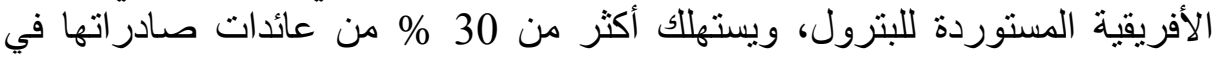
المتوسط، وتخصص بعض الدوردة للترول الأفريقية، ومنها كينيا والسنغال أكثر من نصف

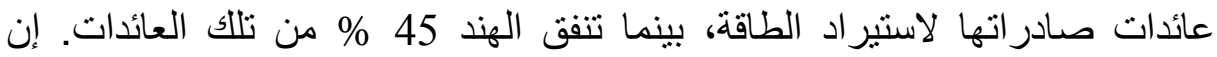
الإستتمار في مصادر الطاقة المتجددة المنو افرة حاليا، يمكن ان يحسن من ألمن الطنات الطاقة بصورة ملحوظة، وبالتالي من الأمن الاقتصادي والطنة المالي. 


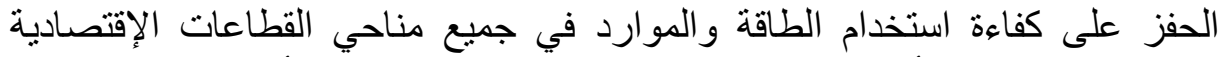

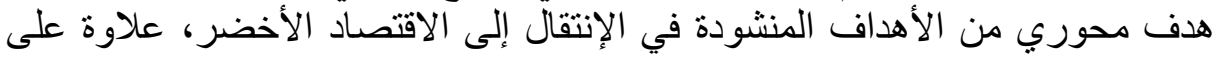

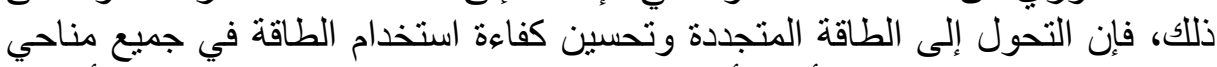

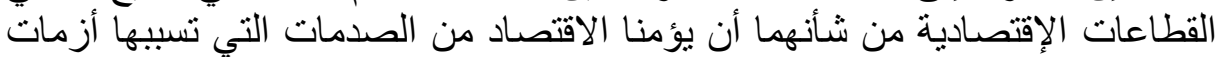

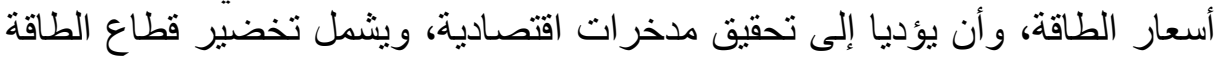

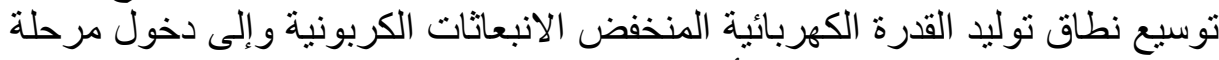

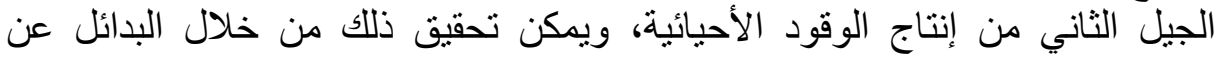

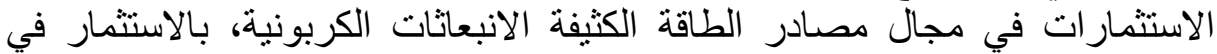

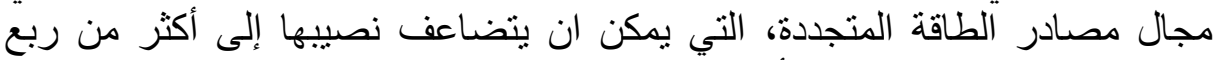

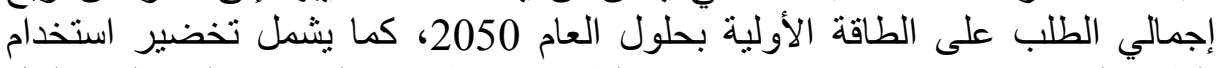

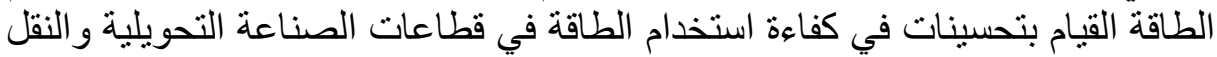
و البناء، و إضافة إلى ذلك، فإن الحلول التي تعنى بالطاقة المتجددة بالاكتفاء بهاء من فن التهاء

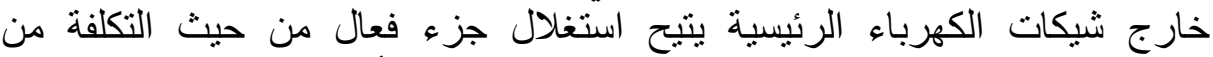

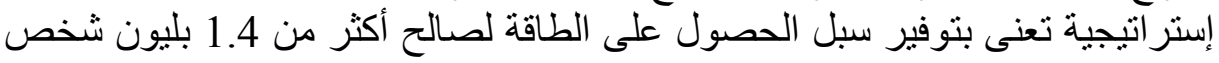

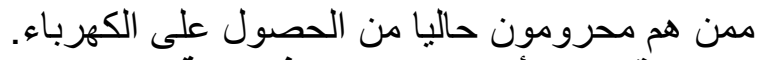
د- الاقتصاد الأخضر يحقى منافع بيئية:

حيث ترتبط المستويات الحالية للنفايات بقوة الدخل، فكلما ارتفعت مستويات الدخل،

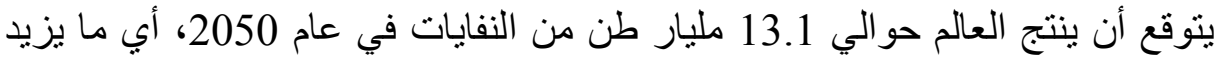

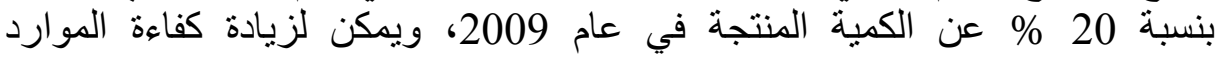

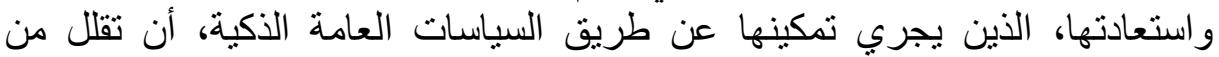

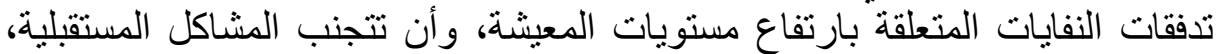

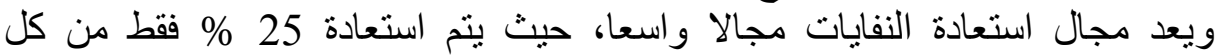
النفايات وتدوير ها، في حين يبلغ حجم السوق العاديات التمي للنفايات من التجميع إلى التدوير،

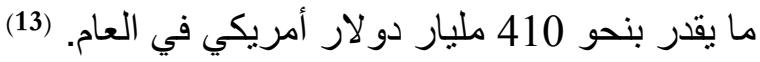

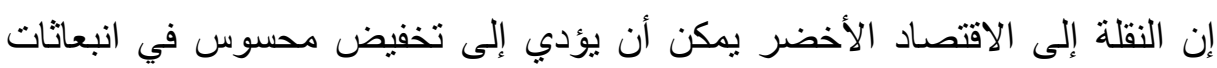

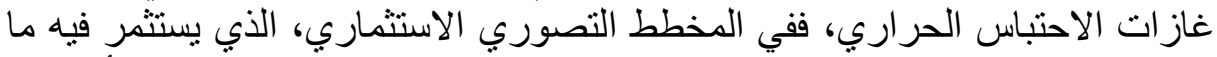

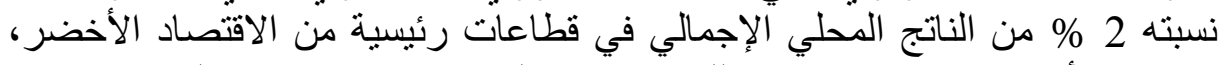

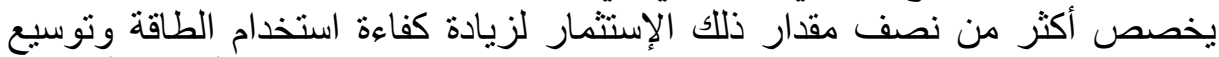

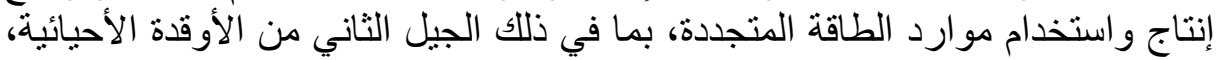

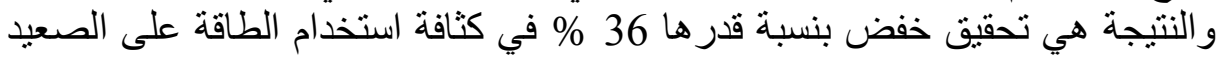

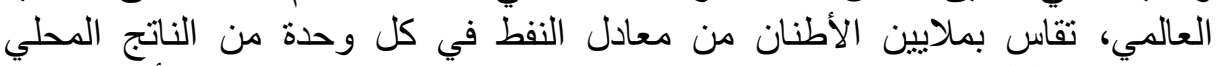

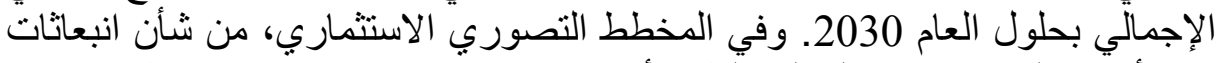

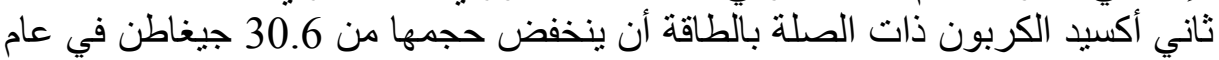

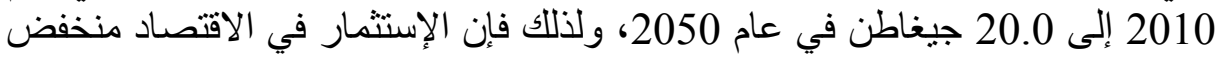

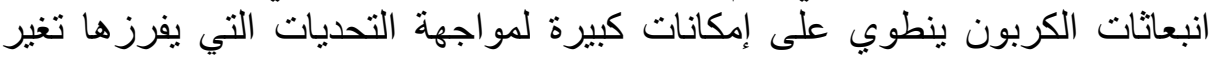

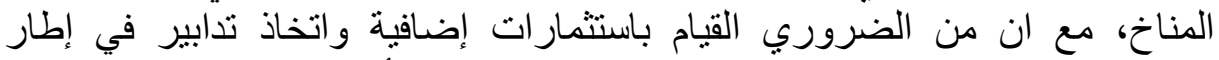

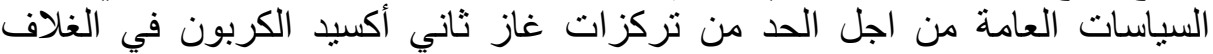
الجوي إلى 450 جزءا من المليون أو لأقل من ذلك الك.

\section{هـ الاقتصاد الأخضر بارك قيمة رأس المال الطبيعي ويستثمر فيه:}

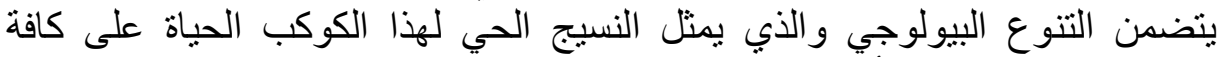

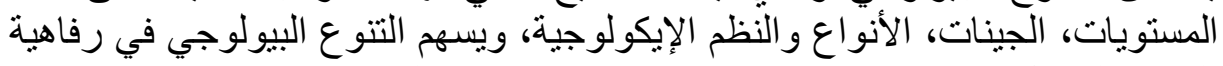

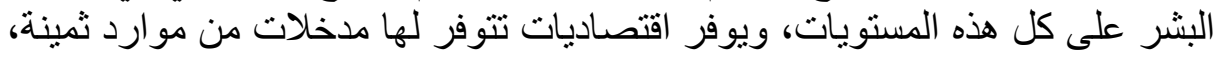


وتتوفر لها خدمات تتظيمية وصولا إلى بيئة عمل آمنة، وتأتي هذه الخدمات غالتيات

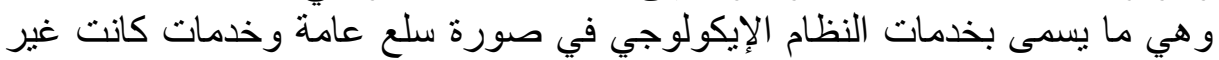

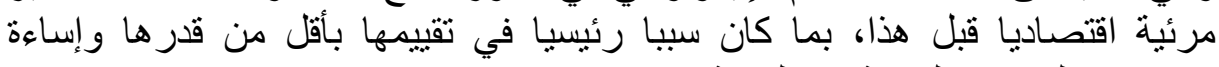

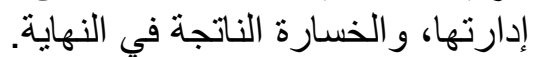

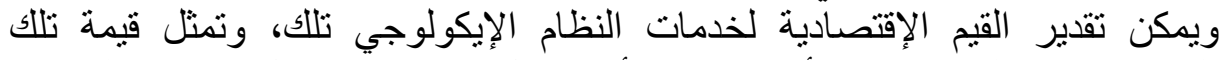

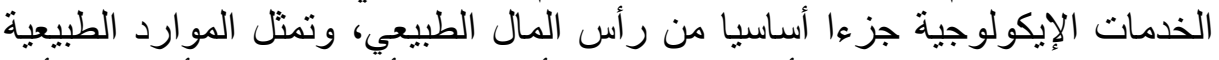

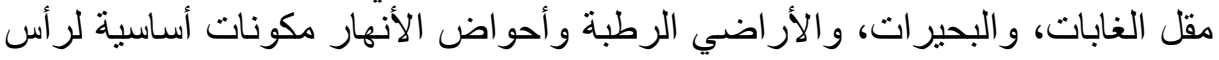

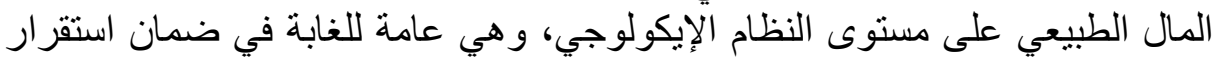

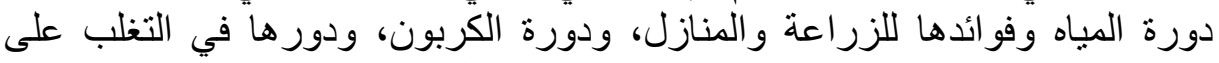

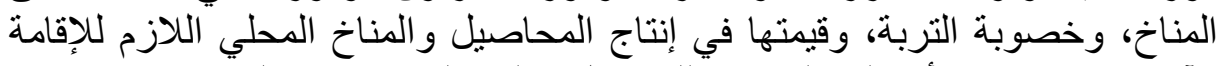

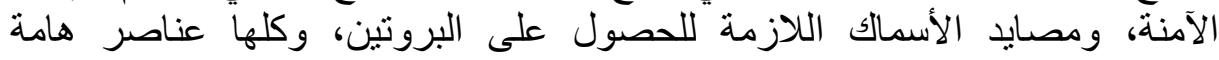

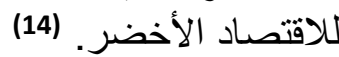
ثانيا: مؤشرات، متطلبات وتحديات والحلول من أجل التحول للاقتصاد الأخضر:

\section{ؤشر ات قياس الاقتصاد الأخضر :}

إن المؤشرات التقليدية مثل الناتج المحلي الإجمالي، تنظر للأداء الاقتصادي من خلال

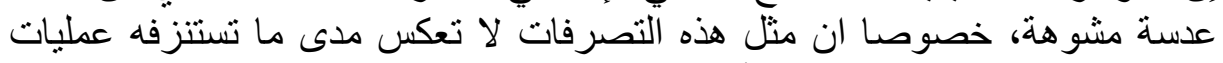

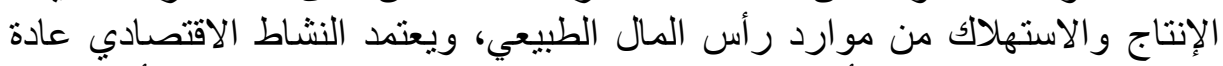

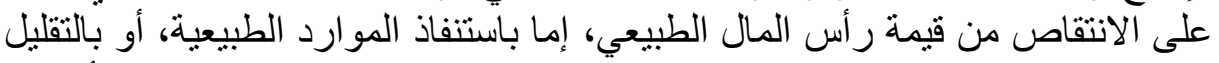

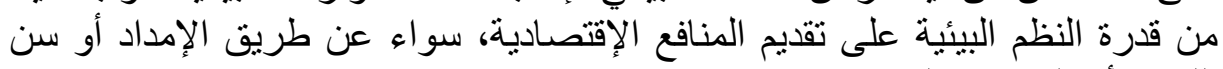
اللوائح أو الخدمات التقافية.

وفي الوضع المثنالي تقيم التغير ات الحادثة التبات في أردة رأس المال الطبيعي بقيمة مالية،

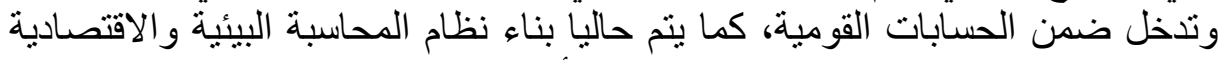
(SEEA) صافي المدخر ات القومية المعدلة بو اسطة الفية البنك الدوائة الدولي.

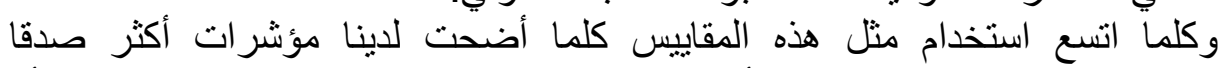

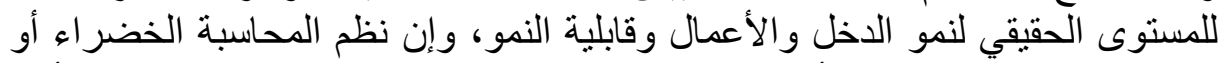

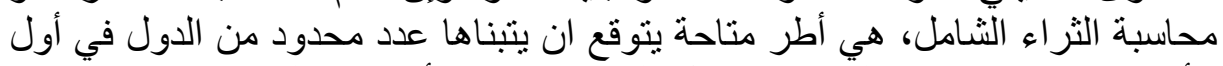

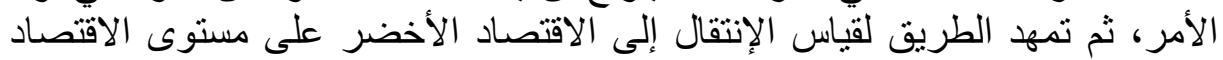

الكلي. (15)

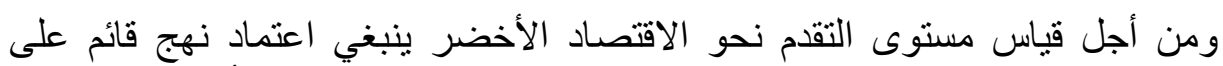

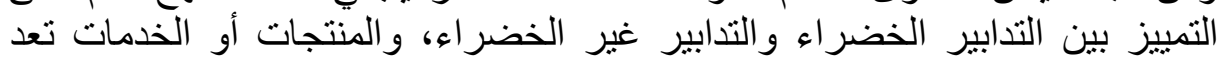

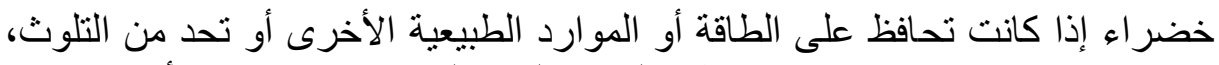

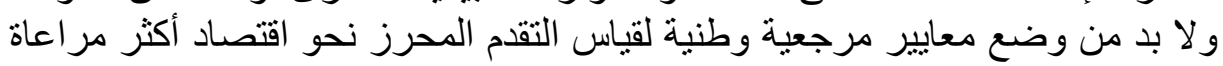

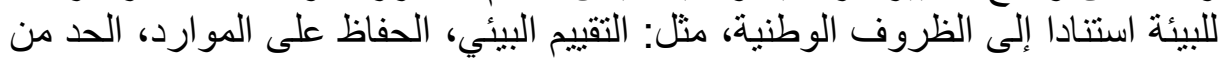

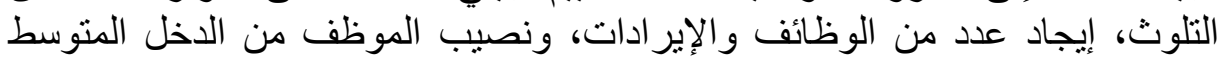

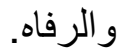
ومع أنه لا توجد مجموعة من المؤشرات المتفق عليها دوليا لقياس مسار التقدم صوب

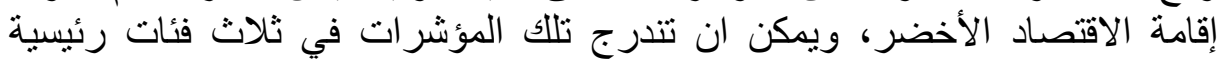

(16) :

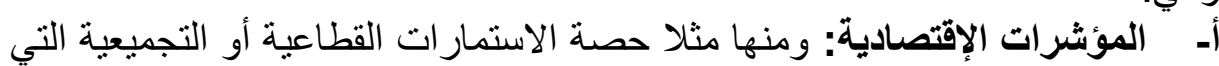

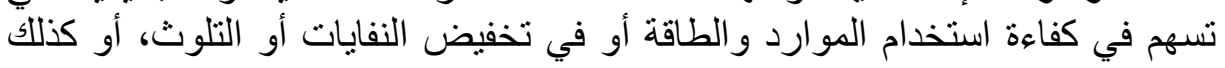


حصة الناتج القطاعي أو التجميعي أو العمالة، التي تفي بالمعايير المقررة بشأن القابلية

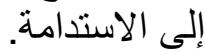

ب- المؤشرات البيئية: والتي تتعلق بالنشاط الاقتصادي، ومنها مثنا كفاءة استخدام

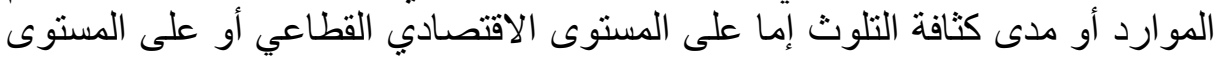

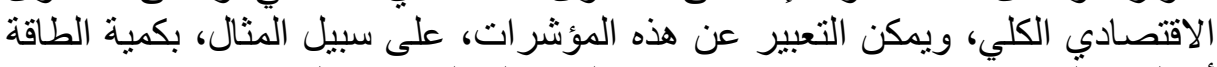
أو المياه المستخدمة لإنتاج وحدة بعينها من النتاج المحلي الإجمالي.

ج- المؤشرات التجميعية: بشأن مسار التقدم والرفاه الاجتماعي، ومنها مثلا فئا

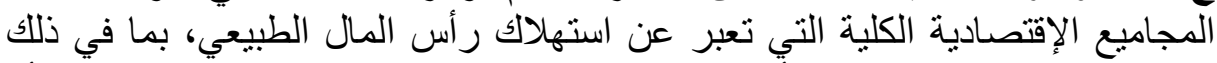

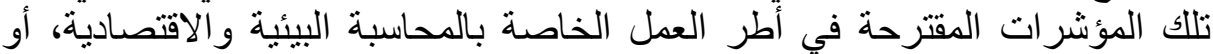

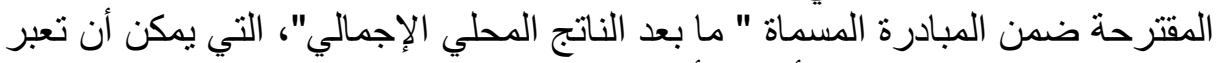

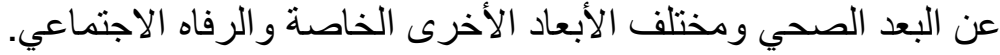

\section{2- متطلبات وتحديات التحول إلى الاقتصاد الأخضر والحلول المقترحة:$$
\text { أـ متطلبات التحول إلى الاقتصاد الأخضر: من أهمها: (17) }
$$

- مر اجعة السياسات الحكومية وإعادة تصميمها لتحفيز التحولات في أنماط الإنتاج و الاستهلاك و الاستثمار ؛

- الإهتمام بالتنمية الريفية بهدف تخفيف الفقر مع زيادة الموارد؛

$$
\text { - الإهتمام بقطاع المياه مع ترشيد الاستخدام ومنع التلوث؛ }
$$

ـ العمل على الاستثمار ات المستدامة في مجال الطاقة و إجراءات رفع كفاءة الطاقة؛ - مضع استراتيجيات منخفضة الكربون للتنمية الصناعية واعتماد تكنولوجيات

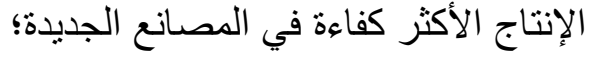

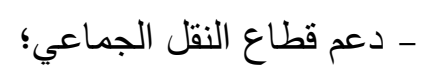

-تبني أنظمة تصنيف الأراضي والتتمية المختلطة الاستعمالات و اعتماد المعايير

$$
\text { البيئية في البناء؛ }
$$

ـ التصدي لمشكلة النفايات الصلبة واستثمار ها فيما هو مفيد وصديق للبيئة.

بـ تحديات التحول للاقتصاد الأخضر: وتتمثل فيما يلي: (18)

- عدم التخطيط المحكم في مجال السياسات التنموية؛

- تفشي ظاهرة البطالة لدى شرائح كثيرة وفي مقدمتها شريحة الثباب، وتحول

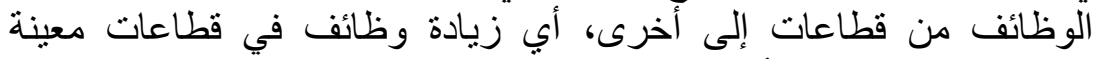

$$
\text { وتر اجعها في قطاعات أخرى؛ فئاع إلى }
$$

$$
\text { - إمكانية نشوء سياسات حمائية وحو اجز فنية أمام التجارة الخارجية؛ }
$$


- تفاقم ظاهرة الفقر، و الافتقار إلى الخدمات الصحية الدنيا و إلى المياه النظيفة، و الافتقار إلى كفاءة استخدام المياه العذبة ومصادر الطفار الطاقة؛

- يعتبر خيار ا مكلفا قد لا ينتج عنه نجاحا أكيدا على الصعيدين الاقتصادي و البيئي،

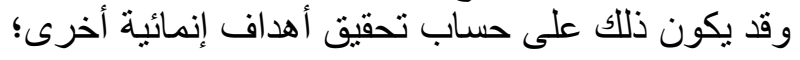

- ارتفاع تكلفة التدهور البيئي في الدول العربية.

ج- الحلول المقترحة لبلوغ الاقتصاد الأخضر: من أجل نجاح مسار التوجه نحو

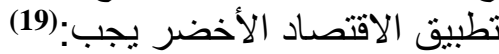

تحديد الحقوق وخلق الحوافز التي تدفع بعجلة النشاط الاقتصادي الأنسار الأخر

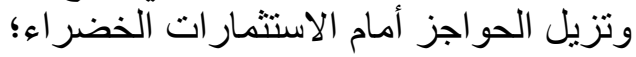

- تحديد أولويات الإستثمار والإنفاق الحكومي في المجالات التي تدعو إلى الدي

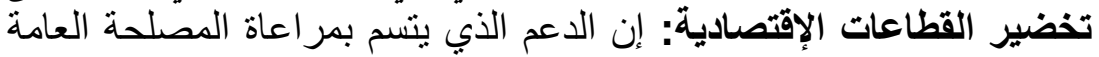

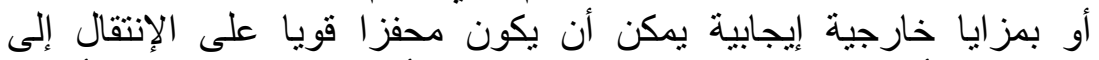

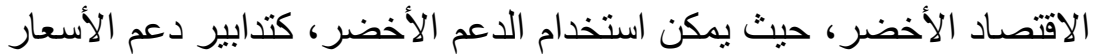

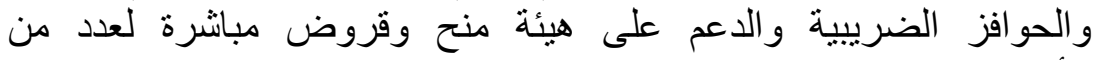

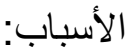

ل للعمل سريعا من أجل تجنب الانحصار في الأصول والنظم غير المستدامة،

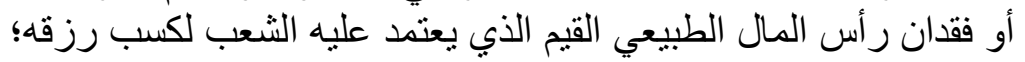

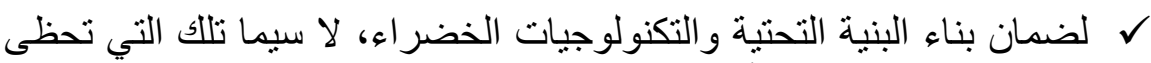

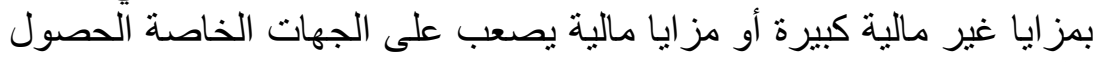
عليها؛

$\checkmark$ ودفع عجلة التوظيف والنمو على المدى الطويل.

- - الحد من الإنفاق الحكومي في المجالات التي تستنزف رأس المال الطبيعي:

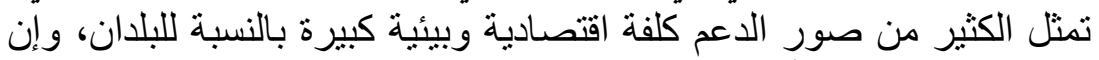

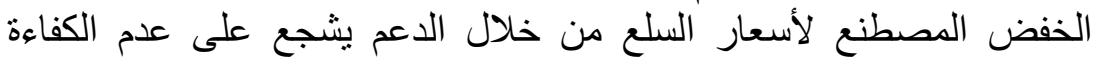

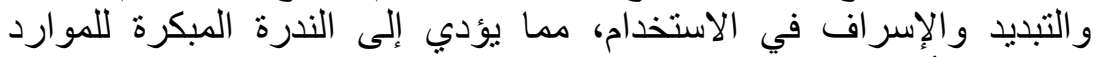

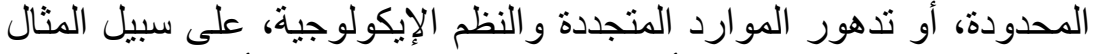

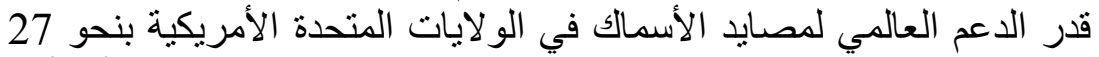

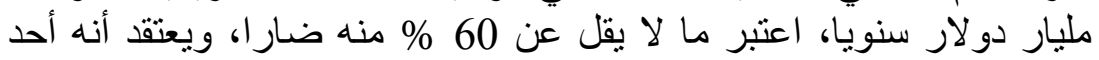

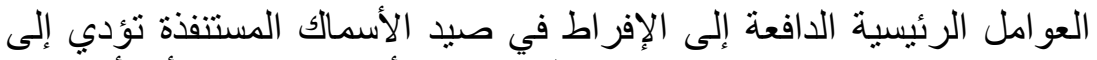

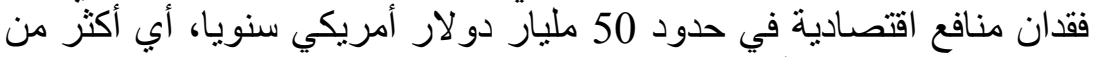
نصف قيمة تجارة المأكو لات البحرية العالمية؛

توظيف الضرائب والأدوات المبنية على السوق لتحويل أذواق المستهلكين

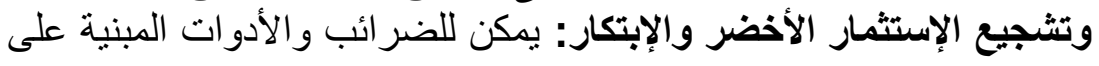


السوق أن تكون وسيلة فعالة لتحفيز الاستثمار ات، فثمة تشويه كبير للأسعار

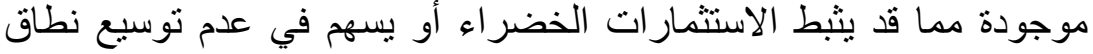

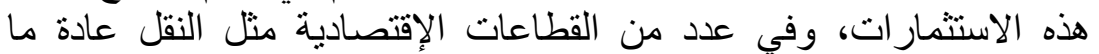
تكون العو امل الخارجية السلبية كالتلوث أو الآثار الإر الصحية أو فقدان الإنتاجية

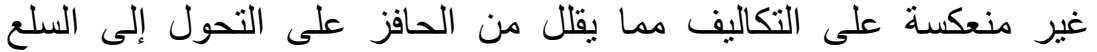

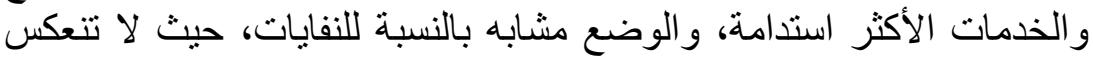

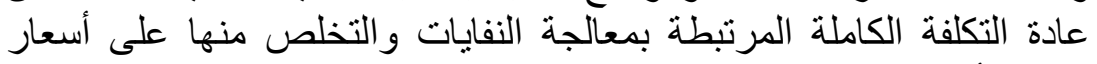

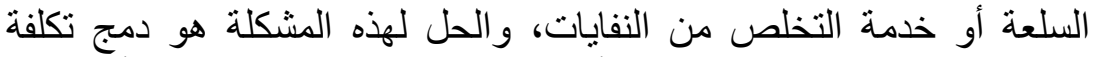

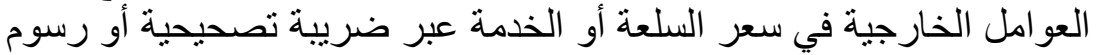
أو جباية، في بعض الحالات باستخدام أدوات أخرى مبنية على آليات اليات السوق،

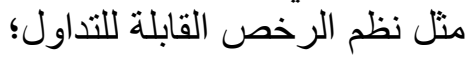

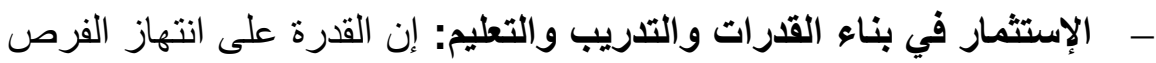

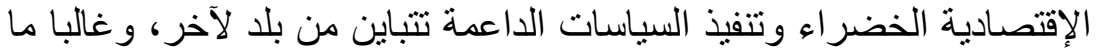

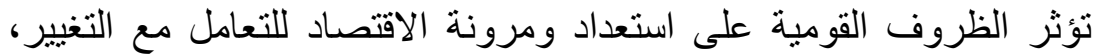

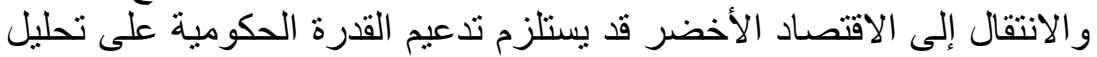

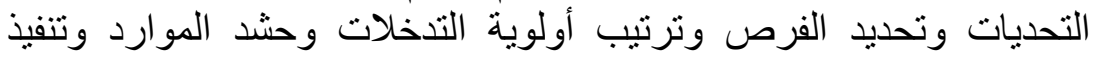
السياسات وتقييم التقدم المحرز، فعلى سبيل المثال تم استخدام الضرائب التبات

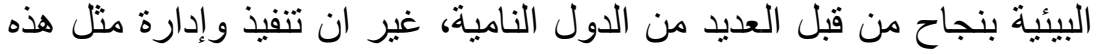

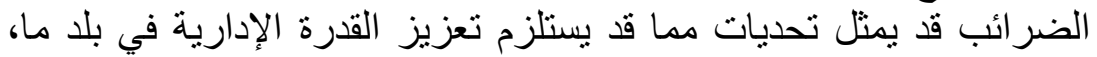

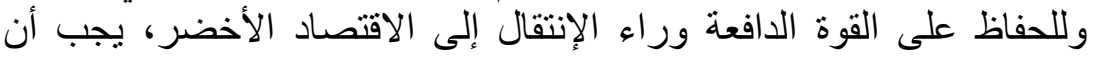

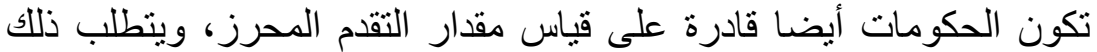
القدرة على تطوير المؤشرات وجمع البيانات وتحليل وتفسير النتائج من أجل فيل توجيه عملية رسم السياسات؛ تورئ

تعزيز الحوكمة الدولية: يمكن للاتفاقيات البيئية الدولية أن تعمل على تسهيل

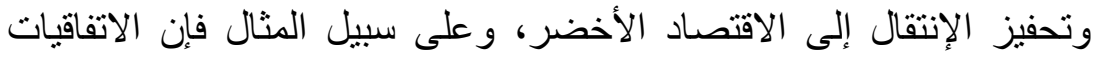

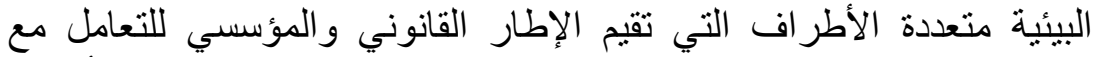

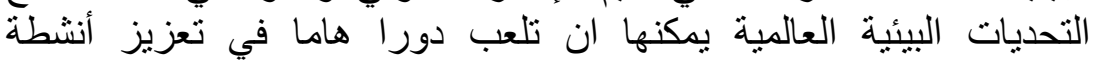

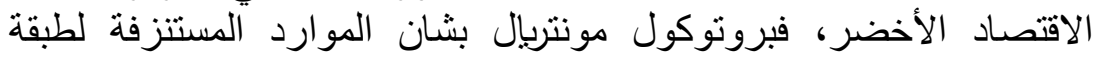

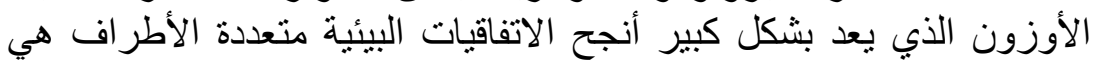

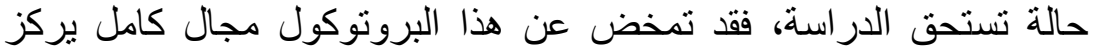
على استبدال و التخلص التدريجي من المو اد المستنزفة للأوزون.

وبالطبع فإن الاتفاق البيئي متعدد الأطر اف ذا الاحتمال الأقوى في التأثير على عملية

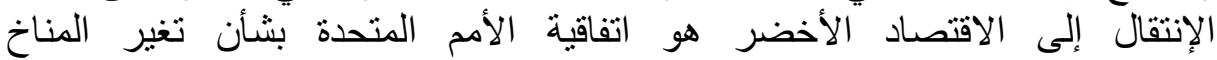

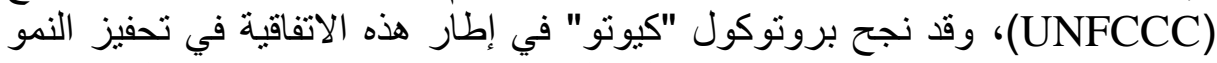

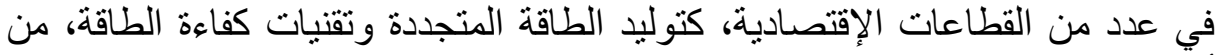

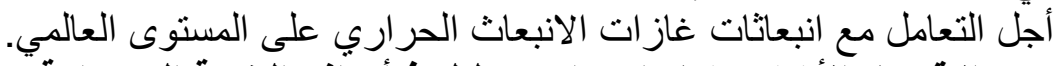
3- الاقتصاد الأخضر خيار استراتيجي لبلوغ أهداف التف التنمية المستدامة:

تتيح أهداف التنمية المستدامة فرصة لإعادة صياغة السياسة الاقتصادية بشأن العناصر

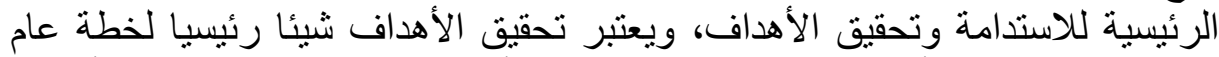

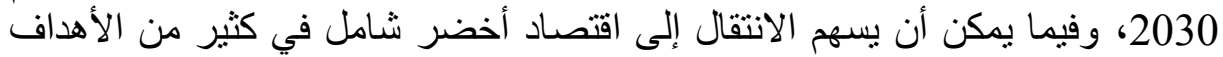
تعد العناصر المختلفة وما يرتبط بها من سياسات لمثل هذا الاقتصاد العاد ذات أهمية كبيرة لتحقيق هدف العمل اللائق والنمو الاقتصادي المستدام وهدف الاستهلاك والإن الإنتاج 


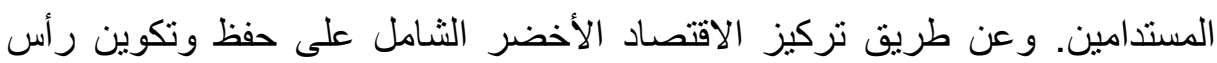

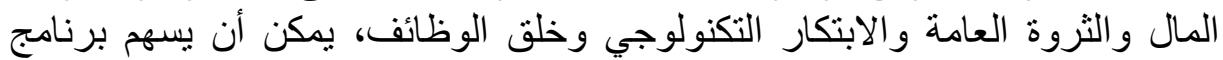

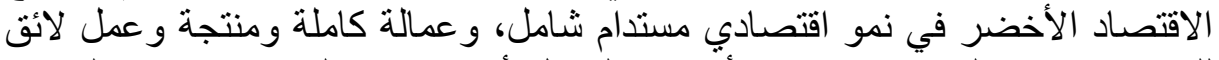

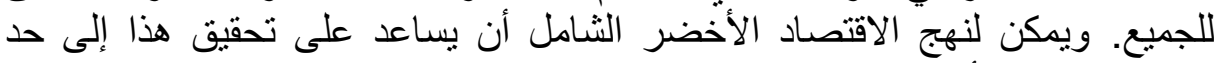

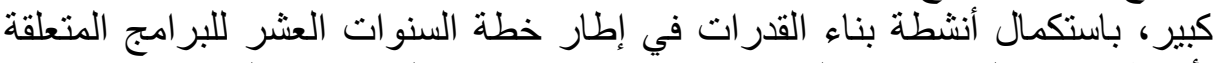

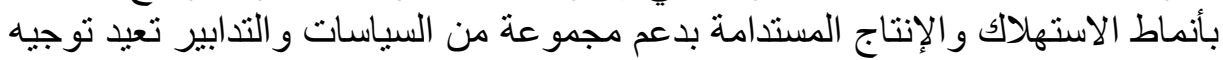

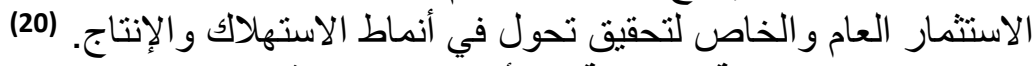

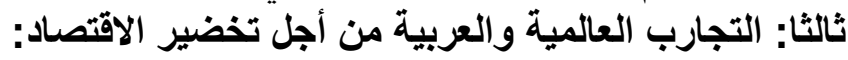

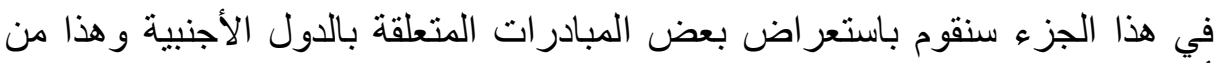

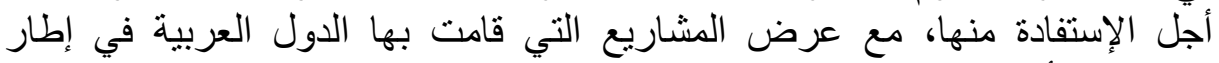

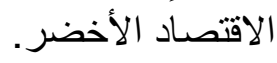

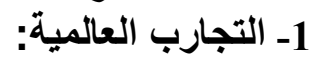

أطلق الصين مؤخرا تكنولوجيات فليلة الانبعاث الكربوني في السلسلة الكاملة لتوريد

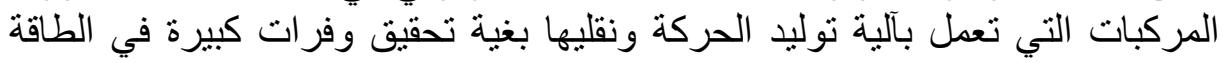

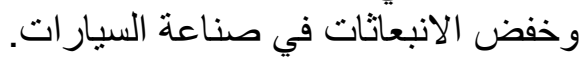
وتكنولوجيات "الطاقة الجديدة" المتقدمة في المركات المركبات التي تعمل بنظام آلية توليد

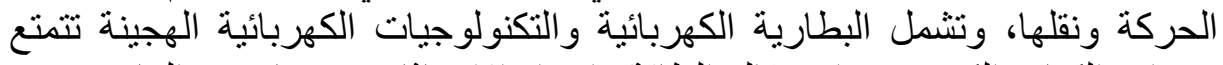

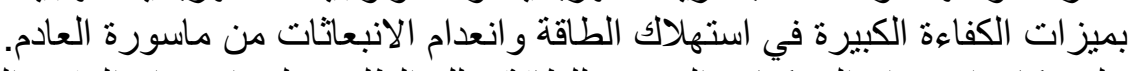

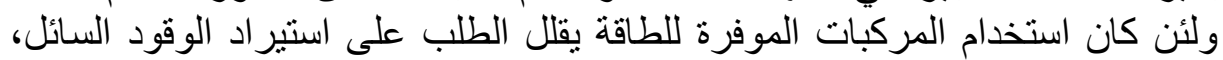

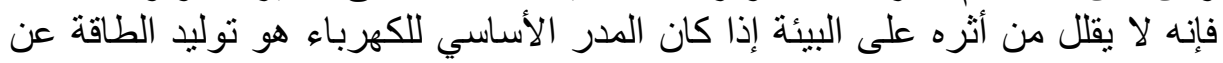

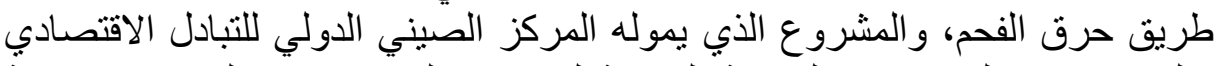

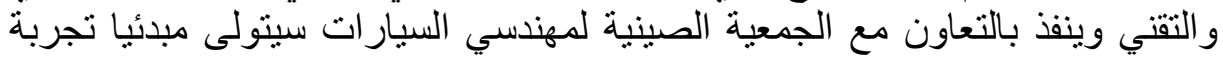

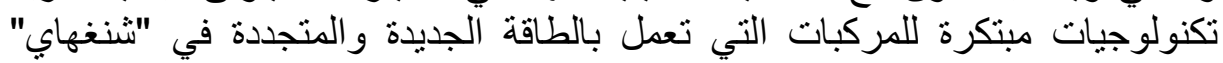

و "يانشنغ". (21) كما طبقت جمهورية كوريا سياسة المسؤولية الممتدة للمنتج (21) (ERP) على التعبئة

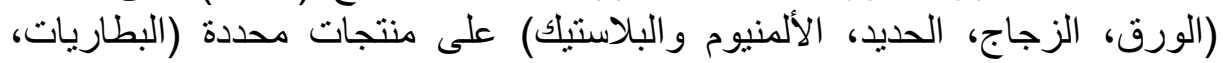

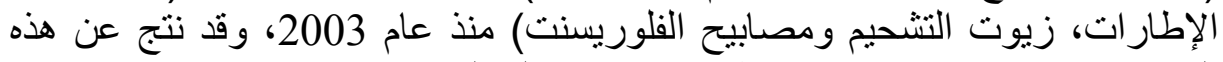

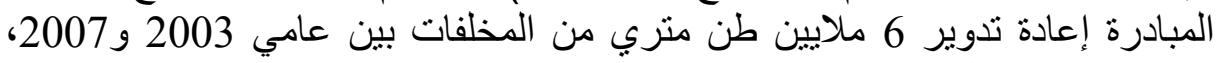

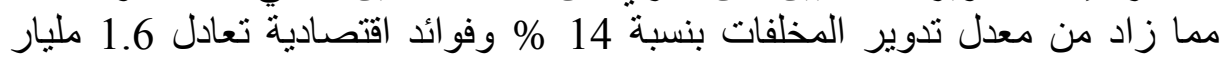
دو لار.

كما فرضت جنوب أفريقيا ضريية على الأكياس البلاستيكية لتقليل القمامة غير

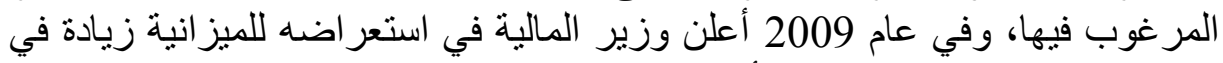

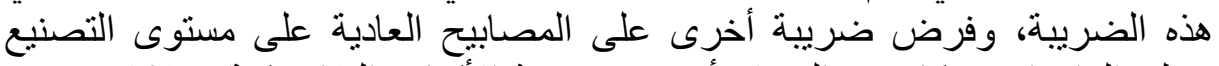

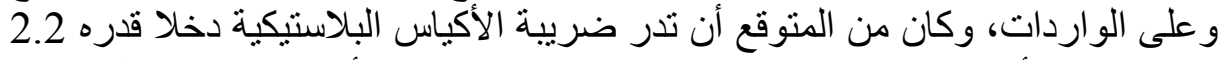

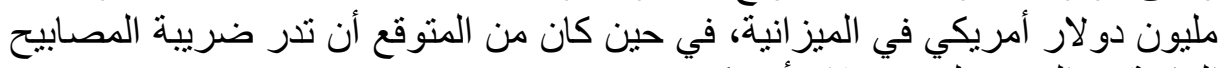
العادية حوالي 3 مليون دولائي في لار أمريكي.

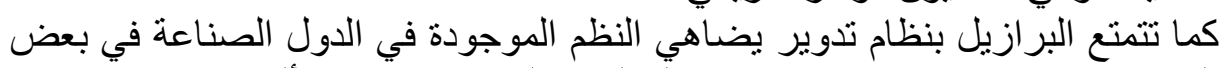

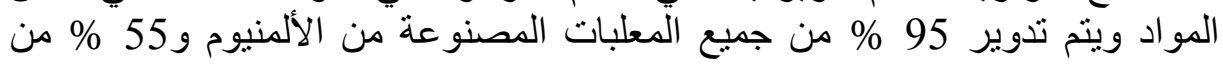

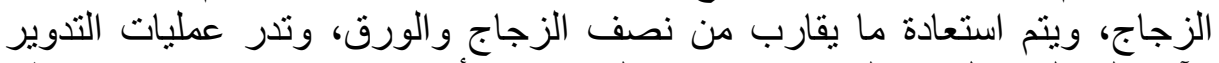

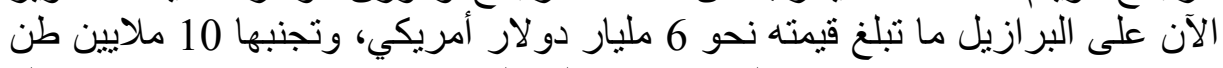

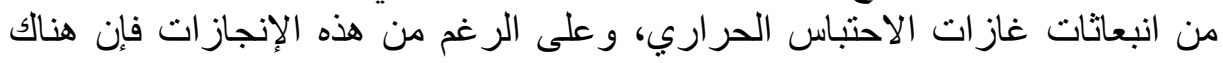


مواد تبلغ قيمتها 5 مليار ات دو لار أمريكي تذهب إلى مقالب القمامة، ويمثل التدوير ما قيمته نحو 0.2 \% من الناتج المحلي الإجمالي.

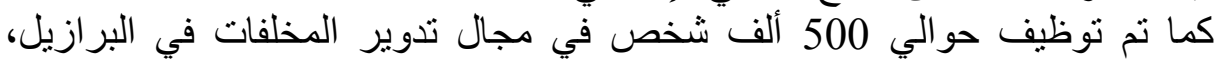

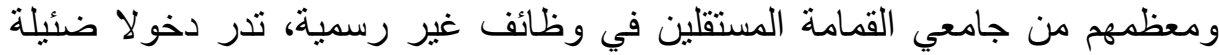

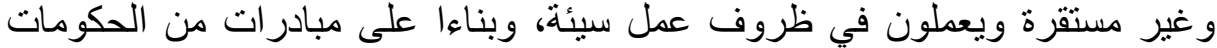

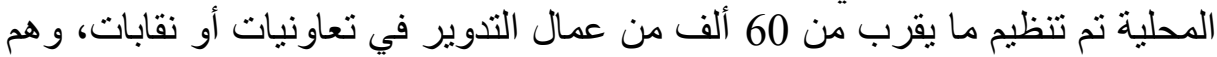

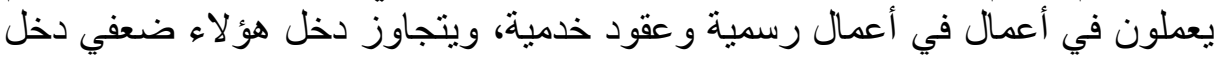

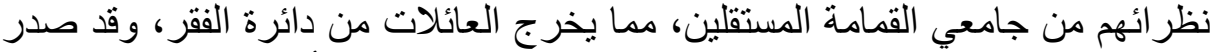

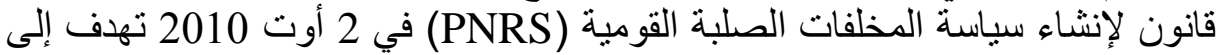

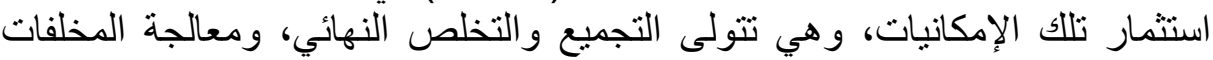

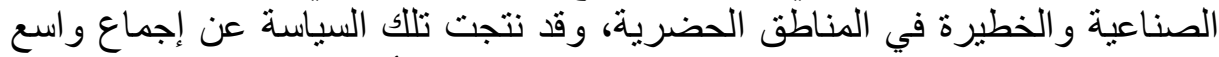
مبني على حوار اجتماعي يشمل الحكومة وقطاع الإنتاج و أصحاب المصلحة في مجال إدارة المخلفات و الأكاديميين.

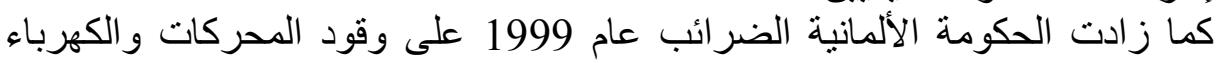

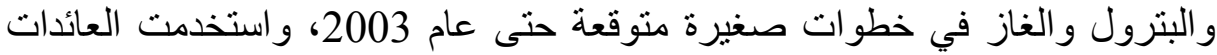

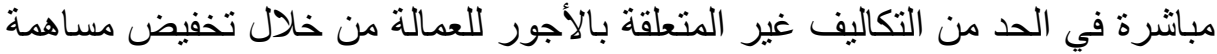
الثريك الاجتماعي في صندوق المعاثات والتقاعد، وتوصلت دراستة داسة عن الآثار

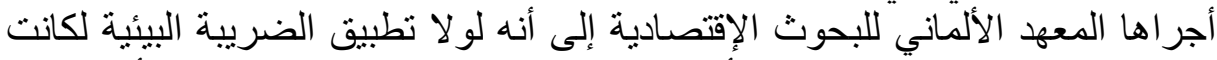

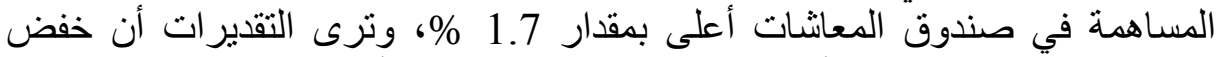
التكاليف غير المتعلقة بالأجور للعمالة قد خلق 250 ألف فرصة الفئ عمل إضافية

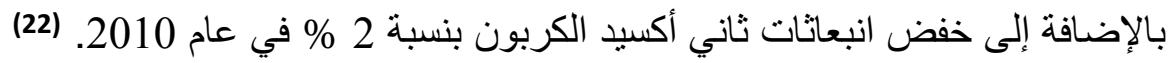
2- المبادرات الناجحة في المنظقة العربية في مجال الاقتصاد الأخضر:

1-2- تجربة المغرب: يتجه المغرب بعزم نحو تشجيع الاقتصاد الأخضر بالنظر

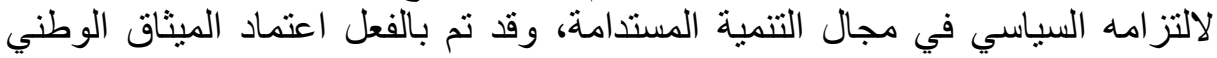

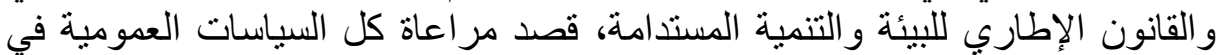
الإستر اتيجية الوطنية للتنمية المستدامة. للفية

لقد تم اعتماد مخطط استثمار أخضر، كما يتم التفكير حاليا في إحداث صنداث الإندوق

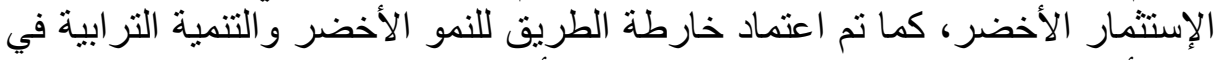

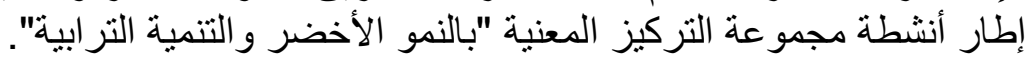

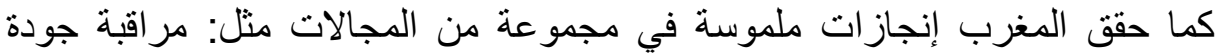

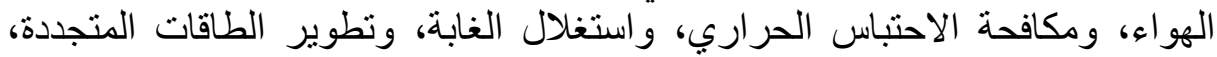

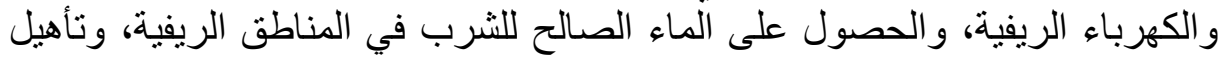

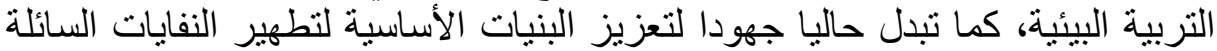

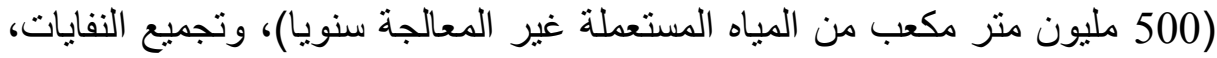

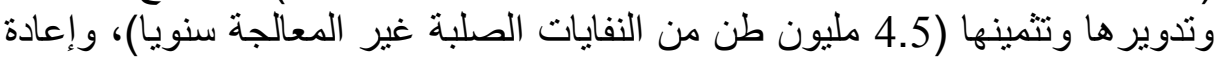

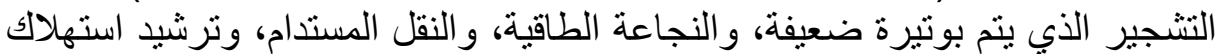
المياه، وتتمية الموارد المائية غير التقليدية.

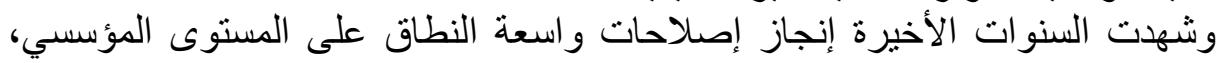

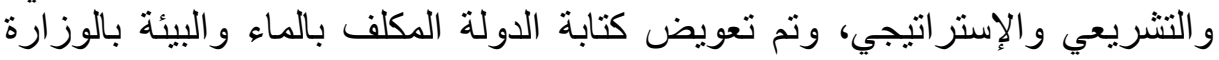
المنتدبة لدى وزير الطاقة والمعادن و الماء و البيئة في عام الإنة 2013، وتم إنشاء وكاءة وكالات

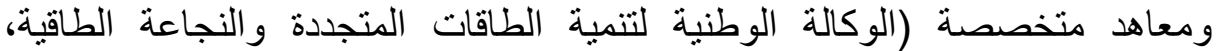
و الوكالة المغربية للطاقة الثمسية، والوكالة الوطنية لتنمية تربية الأحياء البحرية، البهاءة الطية 
معهز الأبحاث في الطاقة الثمسية والطاقة المتجددة)، كما تم أيضا إطلاق مشاريع

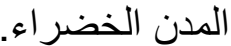
وأنجزت العديد من دراسات التقييم البيئية الإستراتيجية (البرنامج الوطني للنفايات

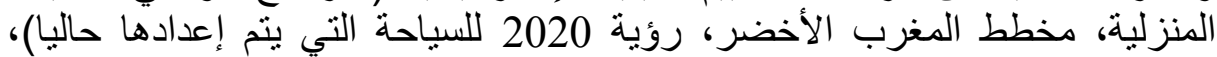
ويتم أيضا إعداد إستر اتيجيتين وطنيتين لحماية البيئة و التنمية المستدامة، وإستة إستر اتيجية

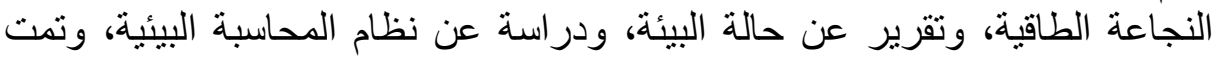

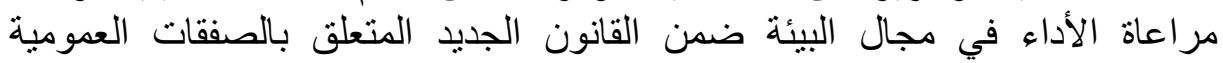
.2014

وتوجد العديد من البرامج القطاعية في طور التنفيذ والتي تساهم في تفعيل الاقتصاد

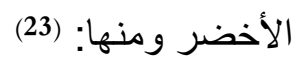

أـ المخطط الثمسي 2020: والذي يهدف لإنجاز 5 محطات بقدرة إجمالية 2000 ميغاو اط أي 14 \% من الاحتياجات من الطاقة الثمسية، والذي سئي سيساهم في

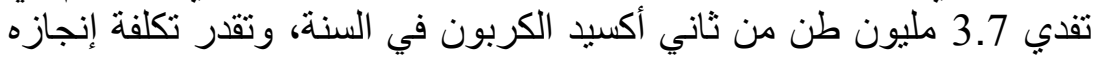
بحو الي 70 مليار در هم؛ مليون

ب- مخطط طاقة الرياح المندمج 2020: و الذي يهدف لإنتاج 2000 ميغاو اط أي

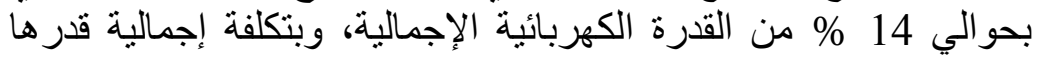

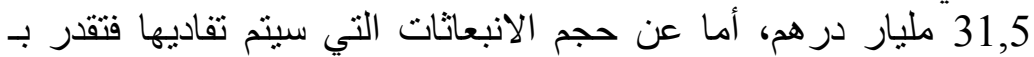
5.6 مليون طن من ثاني أكسيد الكربون في السنة.

ج- البرنامج الوطني للاقتصاد في مياه السقي 2030: ومن أهدافه:

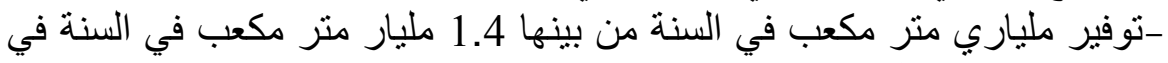

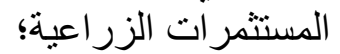

- الإنتقال نحو السقي الموضعي على مساحة 550000 هكتار في حدود سنة 2020

- 330000 هكتار مجهزة بأنظمة عصرية للاقتصاد في المياه في سنة 2013، أي حوالي 24 \% من المساحة الإجمالية مقابل 11 \% سنة 2017. دـ النجاعة الطاقية ــ البناء والصناعة والنقل في سنة 2030: ومن أهدافه:

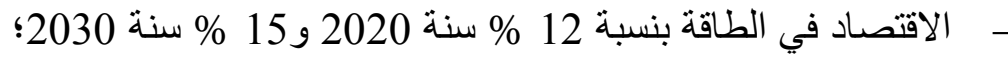
- - تقليص انبعاثات الغاز ات الدفينة بنسبة 35 \% المتعلقة بالمركبات؛ - - تقليص الفاتورة الطاقية بنسبة 15 \% بحلول 2030؛ - توفير 40000 منصب شغل في حدود سنة 2020؛ - تطبيق التسعير المتفاوت في استهلاك الكهرباء؛ - ق قانون النجاعة الطاقية في البناء.

هـ البرنامج الوطني للنفايات المنزلية والمماثلة لها: ومن أهدافه:

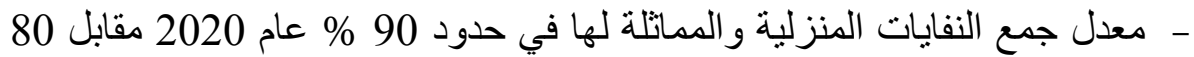
\% عام 2013؛ 


$$
\text { - معدل التدوير } 20 \text { \% في عام 2020؛ }
$$

- - بلوغ نسبة 100 \% من المطارح المر اقبة في المناطق الحضرية عام 2025؛

$$
\text { - توفير أكثر من } 11000 \text { منصب شغل مباثر. }
$$

و- المخطط الوطني لتطهير النفايات السائلة: حيث تقدر تكلفة هذا الإستثمار حوالي 43 مليار در هم، ومن أهدافه:

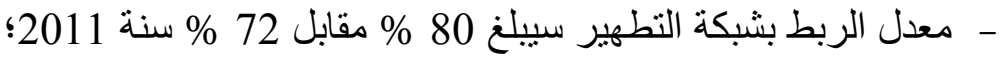
- معدل تطهير مياه الصرف الصحي سيلغ 60 \% مقابل 24 \% سنة 2011؛ - معالجة مياه الصرف الصحي و إعادة استخدامها بنسبة 50 \% سنة 2020 و100 \% سنة 2030؛ معاه - توفير أكثر من 10000 منصب شغل مباشر.

ز- توفير الاعم المالي من خلال استحداث أجهزة ذات المنفعة الإيكولوجية: وتتمثل في: (24) لالصندوق الوطني للبيئة: والذي يساهم في تمويل بر امج التأهيل البيئي؛ ل صندوق التطهير السائل والمياه العادمة: والذي يهدف لتمويل مشاريع التطهير؛ ل صندوق الحد من التلوث الصناعي: من خلال دعم مشاريع الحد من التلوث الصناعي في الوحدات الصناعية والحرفية

ل صندوق التنمية الطاقية: ومهمته مر افقة الإستر اتيجية الطاقية في مجالات الطاقة المتجددة و النجاعة الطاقية؛

ل صندوق التنمية الفلاحية: من أجل تشجيع الاستثمار ات الفلاحية؛

ل صندوق مرافقة إصلاحات النقل: لدعم مشاريع الطرقات وتجديد حظيرة النقل؛ ل صندوق الحسن الثاني للتنمية الإقتصادية والاجتماعية: للمساعدة المالية للبر امج

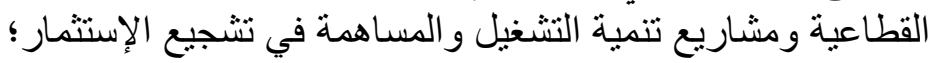
$\checkmark$ ح- الإطار القانوني للاقتصاد الأخضر في المغرب الإبنة

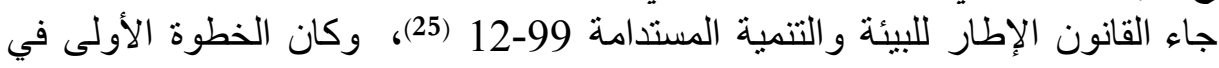

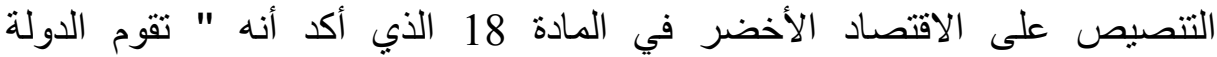

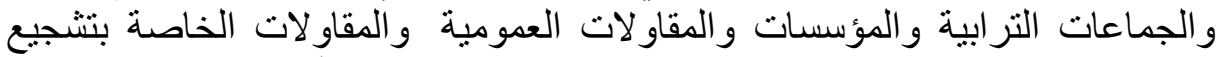

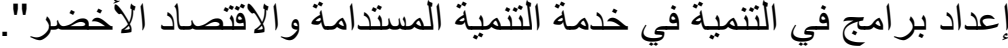
أما على مستوى التنظيم الإداري، فبعد أن كانت السلطة الحكومية المكلة المكلفة بالبيئة وهي

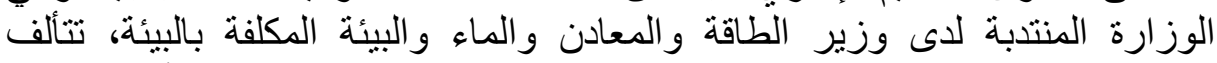

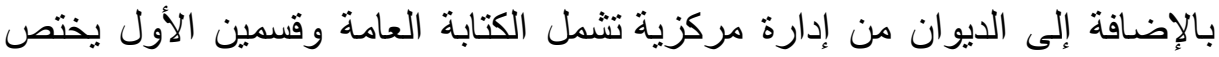


بالمشاريع النموذجية ودر اسات التأثير على البيئة (26)، و الثاني يهتم بالميز انية والموارد

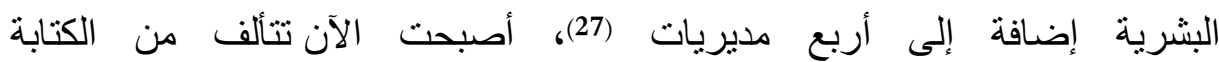

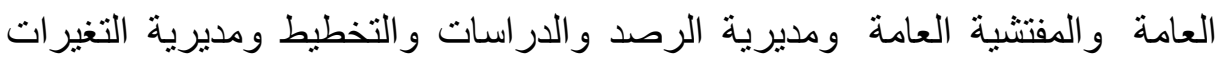

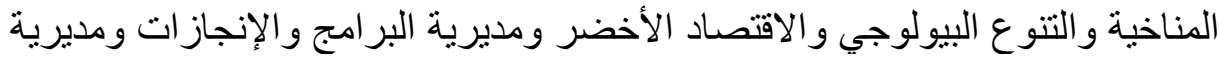

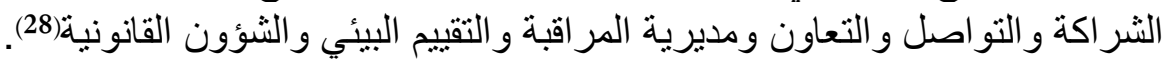

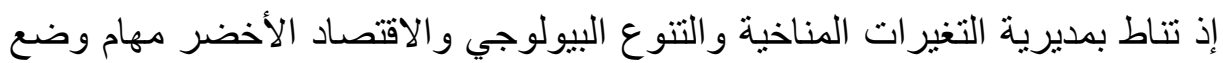

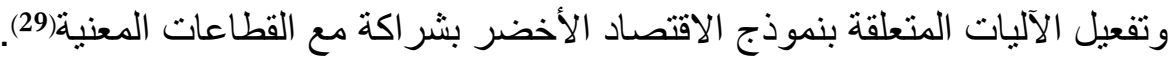

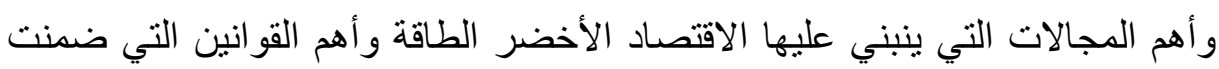

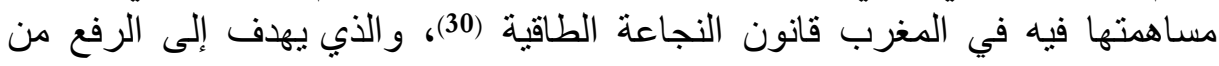

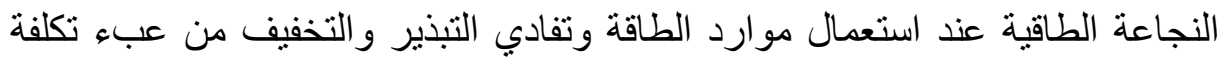

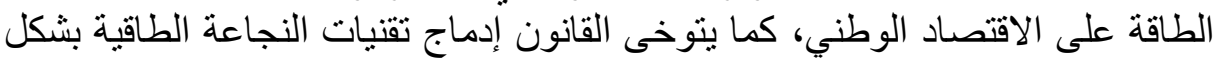

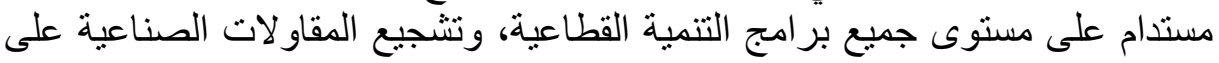
ترشيد استهلاكها من الطاقة.

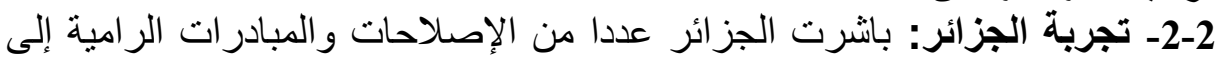

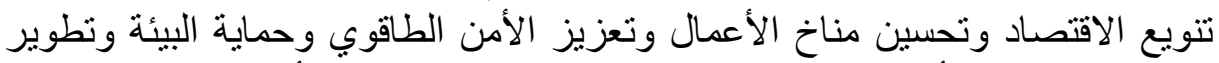

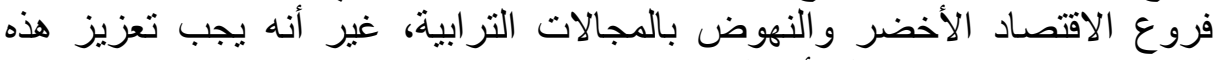

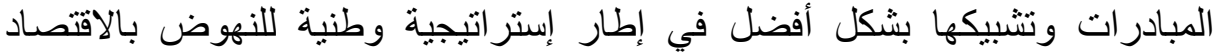

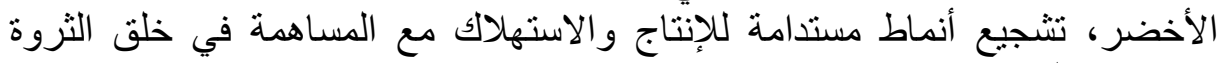
وفرص عمل جديدة.

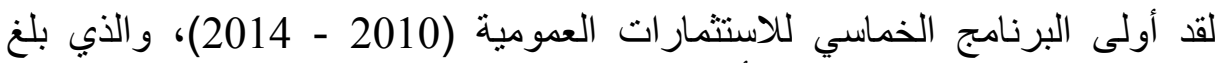

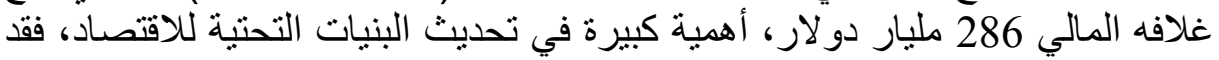

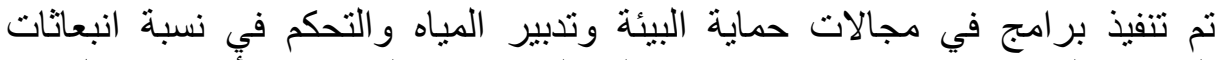

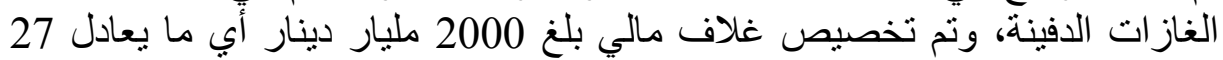

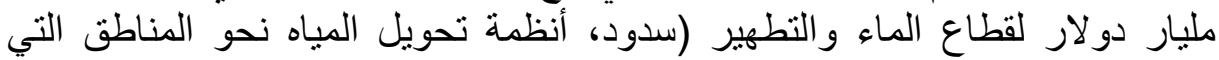

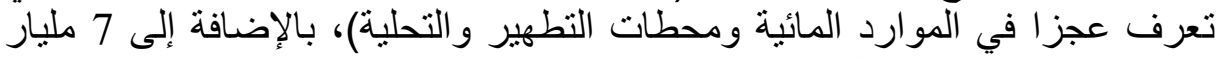

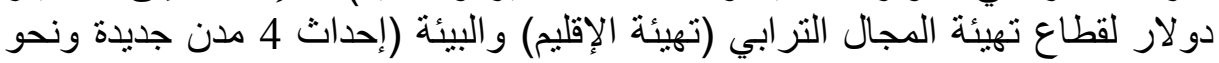

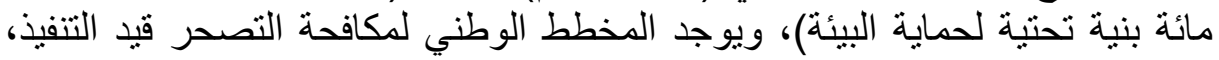

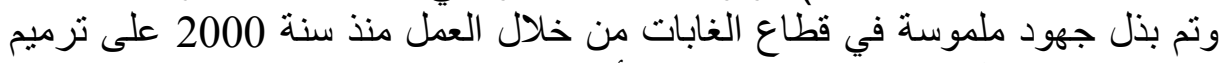

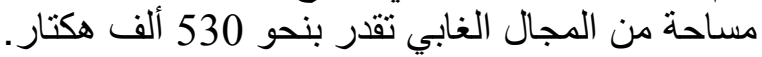

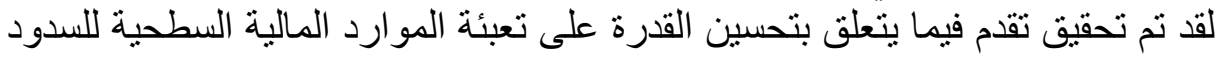

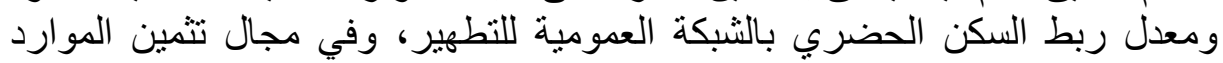

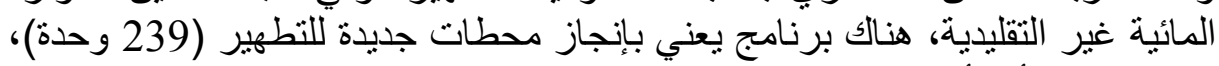

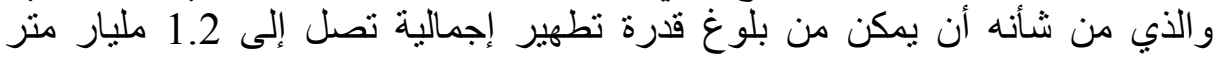

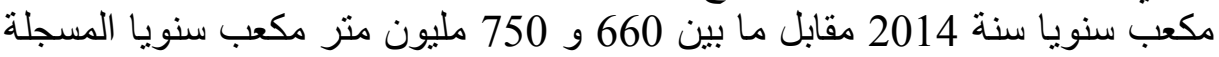

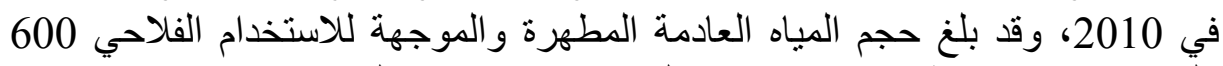

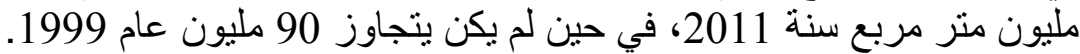

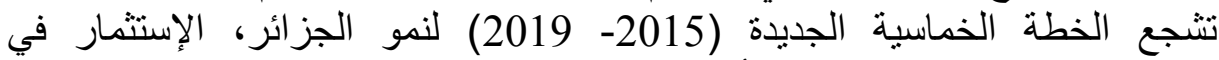

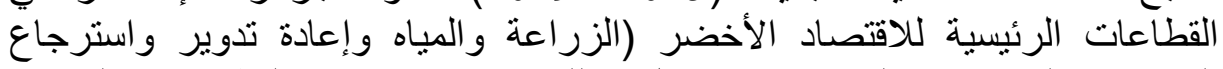

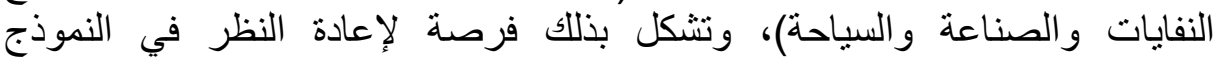

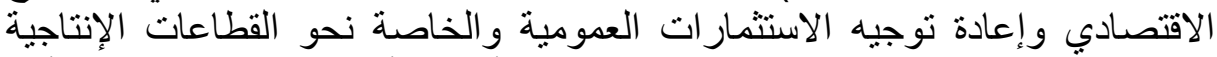

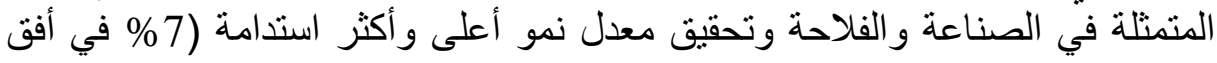


2017)، كما يجب توجيه الجهود نحو التكوين والبحث و الإبتكار في المهن الجديدة

كما طبقت الجزائر إستراتيجية وطنية للبيئة والتنمية المستدامة (2002- 2012) ومخطط لتهيئة المجال الترابي اليخطط الترطية الوطني لتهيئة الإقليم (2050) (2010- 2030) ومخطط وطني للمناخ (2015- 2050) و الذي يوجد في مرحلة الاستكمال، و البرنامج

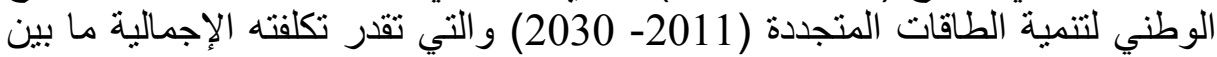

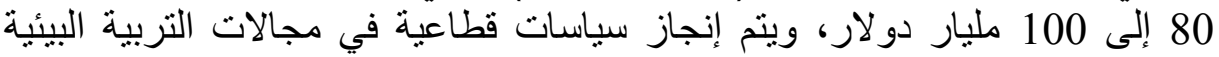
و الموارد الطاقوية، اقتصاد الماء وملاعمة قطاع الماعة الموارد المائية مع التغيرات الأية المناخية

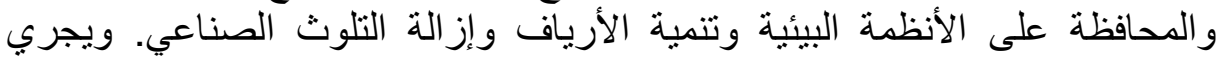

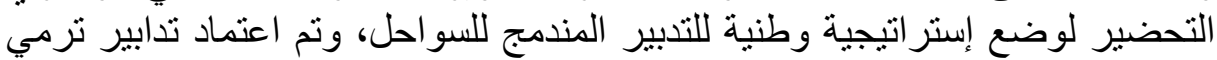

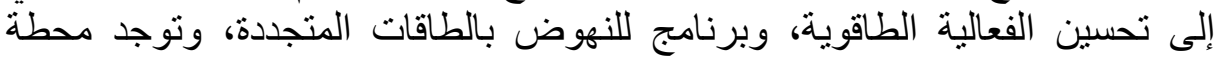

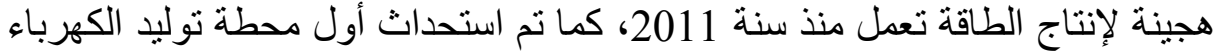

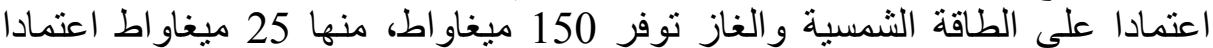

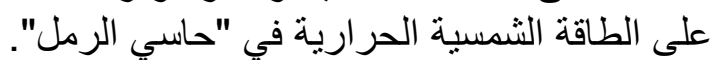

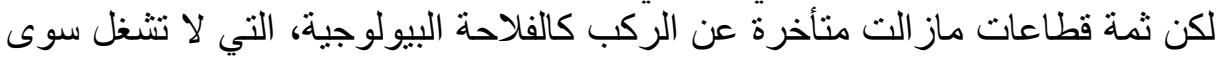

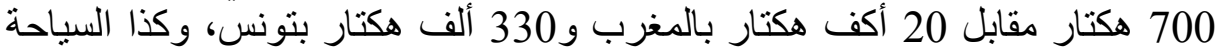
البيئية وتدبير النفايات وتنمية الطاقات المتجددة التي ماز الت الت في مرحلة التجارب

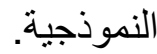
كما اعتمدت الجزائر برنامج وطني لتطوير إمكانات الطاقات المتجددة وكفاءة الطاقة

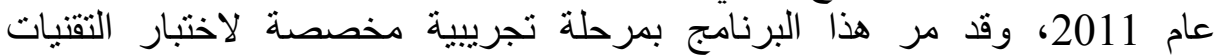

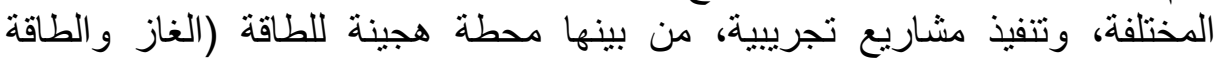
الثمسية) بـ "حاسي الرمل"، محطة الطاقة الضوئية بـ "غرداية" ومحطة طاقة الرياح

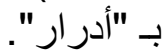

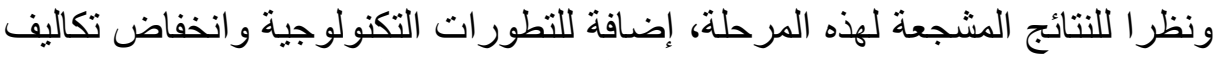

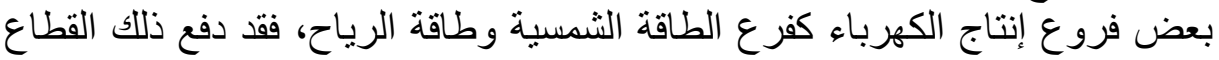

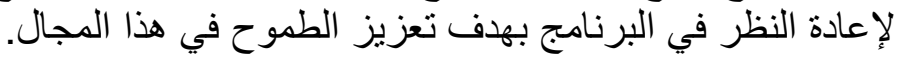

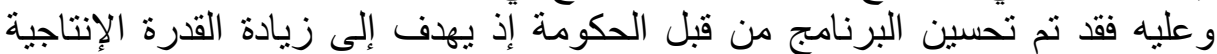

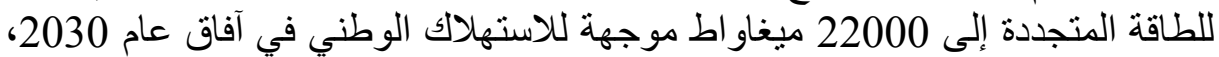

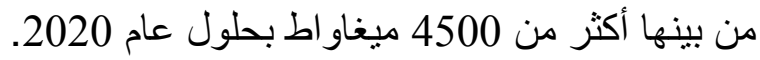
يخص تطوير الطاقات المتجددة في إطار هذا البرنامج طاقة الرياح، الطاقة الثمسية، الطاقة الثمسية الحراراية (CSP)، التوليد المشترك للطاقة، الكتلة الحيوية والطاقة الطاقة الطية الحر ارية الأرضية. يهذف هذا البرنامج إلى إنتاج طاقة متجددة تساهم بـ 27 \% 27 في ميز ان إنتاج الطاقة

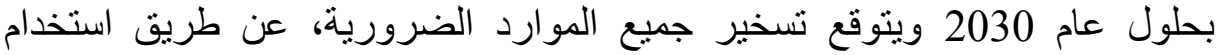

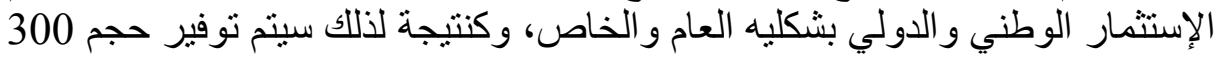
مليار متر مكعب من الغاز الطبيعي.

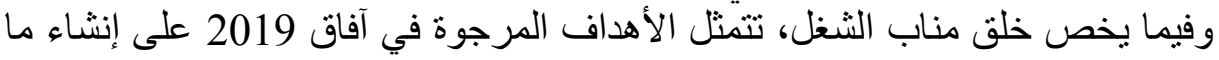

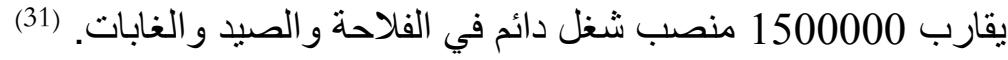

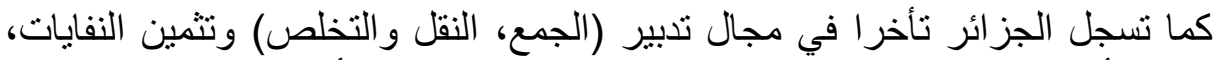

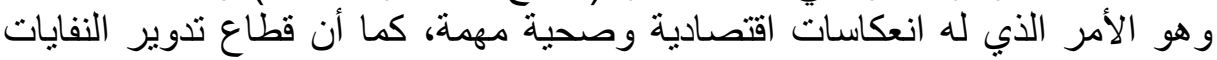

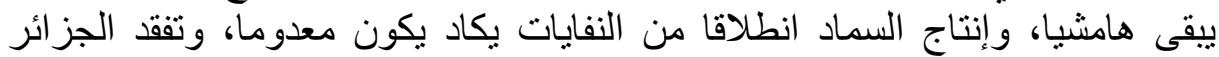
300 مليون أورو سنويا بسبب عدم اعتماد تدوير النفايات. 
ويسعى البرنامج الوطني للتدبير المندمج للنفايات الحضرية إلى تقليص إنتاج النفايات

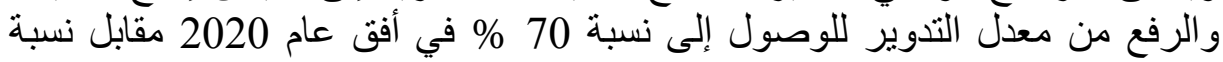

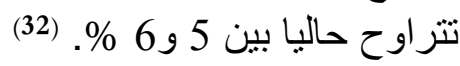

-3-2 تجربة الأردن: يمكن أن يؤدي الاقتصاد الأخضر إلى رولى رفد الإير ادات بمبلغ 1.3

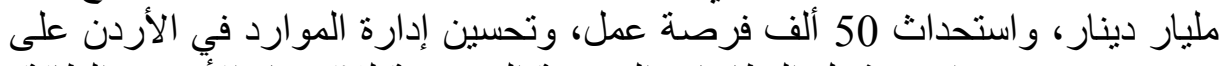

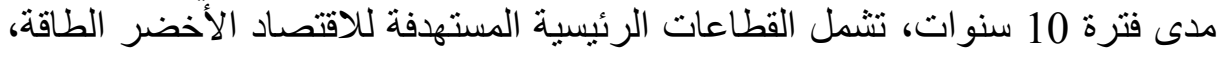

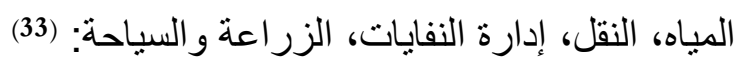

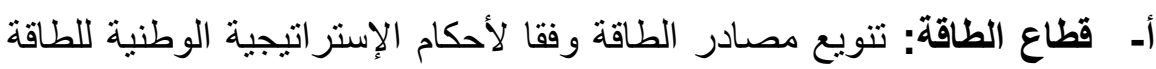

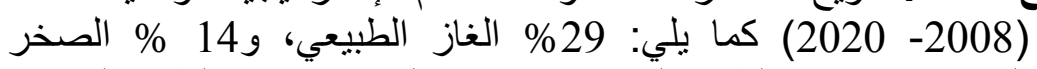

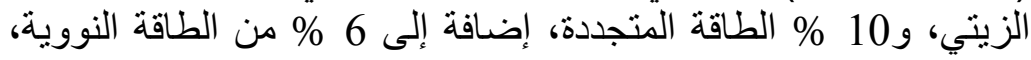

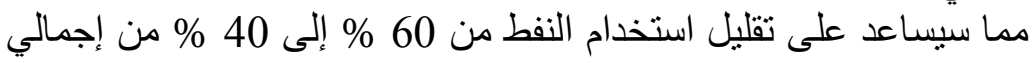

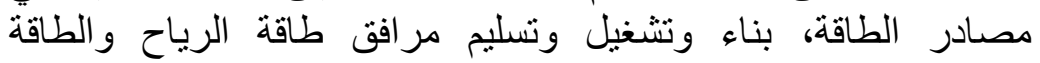

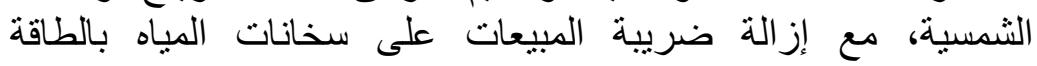

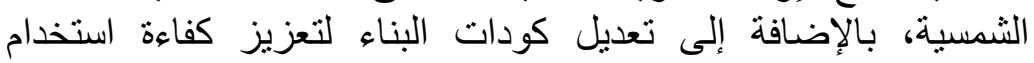

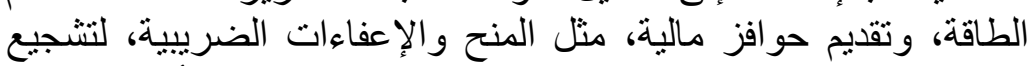

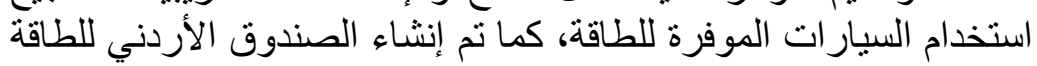

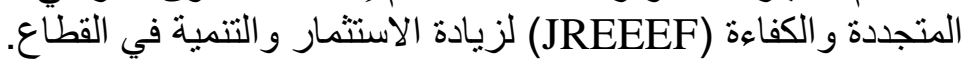

بـ قطاع النقل: مواصلة السعي لتطبيق إستر اتيجية عمان للنقل العام لزيادة خيار ات

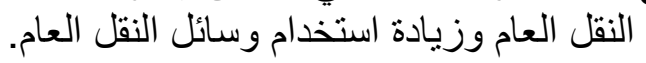

ج- قطاع المياه: وتتضمن تحسين المحافظة على المياه ومعالجتها، وإطلاق جهود من

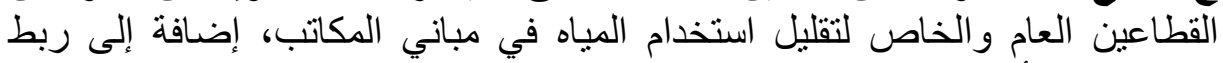
المزيد من الأسر في نظام الصرف الصحي (35 \% غيام الهير موصولين) بهدف زيادة

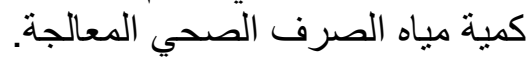

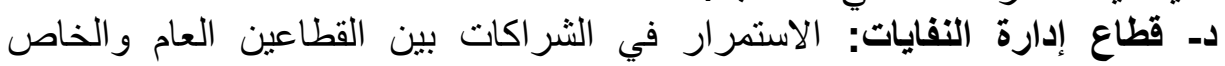

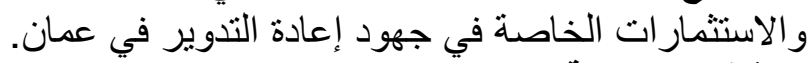

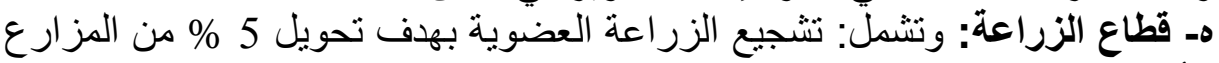

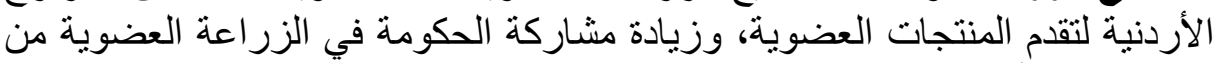

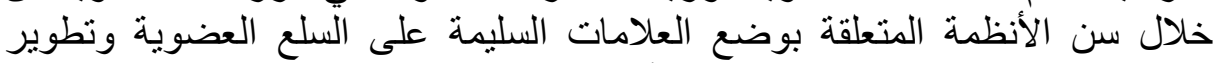

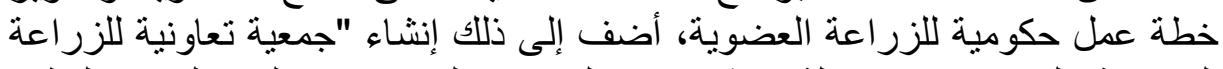

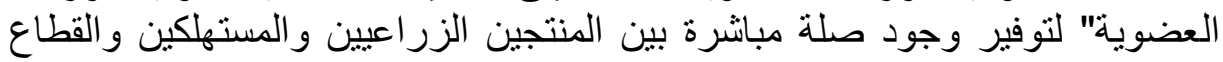

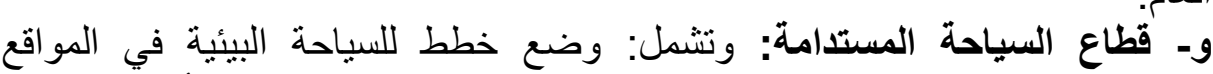
الطبيعية مثل البحر الميت، مع توجيه جهود المحافظة إلى الفنادق وأماكن الإقامة

ز- قطاع البيئة: وتركز على زيادة تعزيز الحفاظ على البيئة من خلال زيادة التنسيق

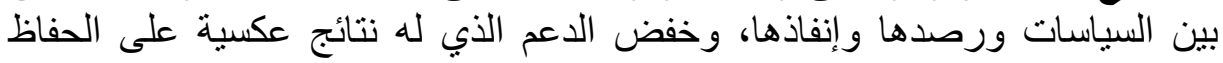

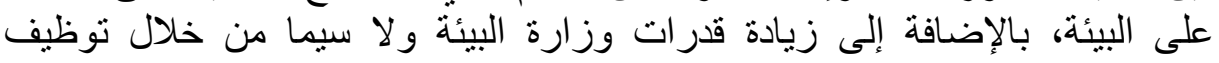


متخصصين مؤهلين وزيادة الإنفاق العام على القضايا البيئية، وهي تشكل حاليا 0.5

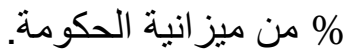

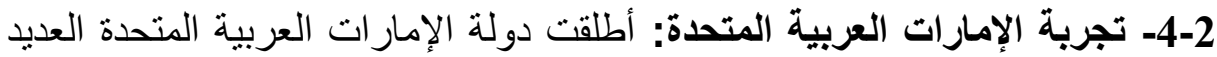

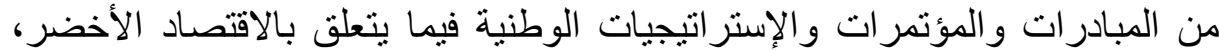

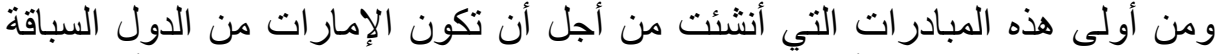

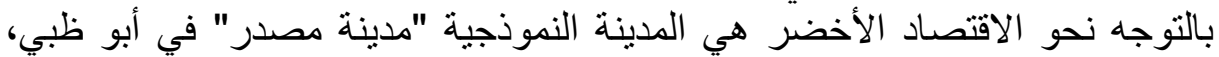

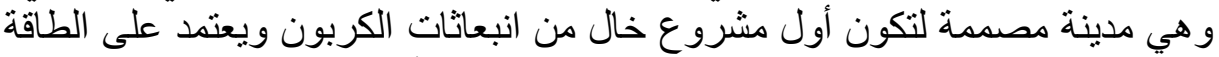

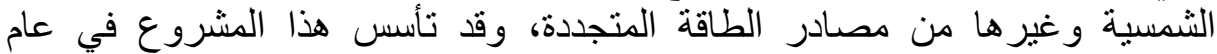
2008، ومن المتوقع أن ينتهي ما بين الأعوام 2020 و و2025، وسئنة وسوف تكون "مدينة مصدر" موطنا لحوالي ما بين

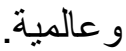

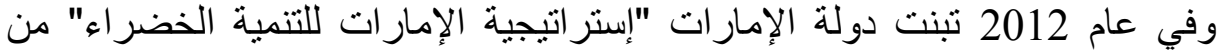

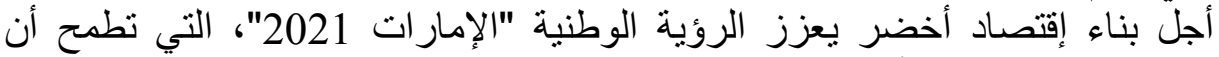

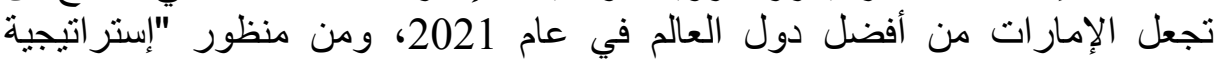

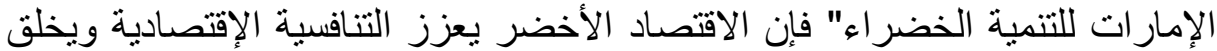
فرص عمل، يجذب الاستثمارات، يدعم الابتكار والمعرفة، ويعزز الأمن الوطني في الإني

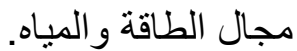
كما عقدت في دبي عام 2014 القمة العالمية للاقتصاد الأخضر بمشاركة أبرز

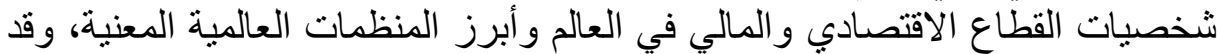

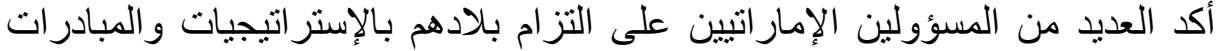

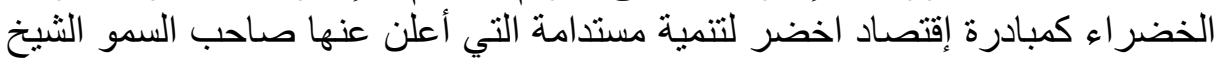

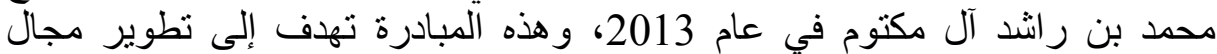

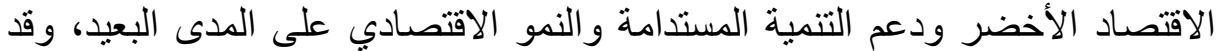

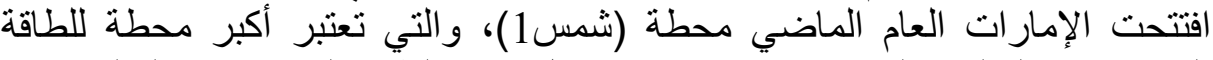
الثمسية في العالم، والتي تنتج 10 \% من مجمل إنتاج الفاج الطاقة الثمسية في العالم.

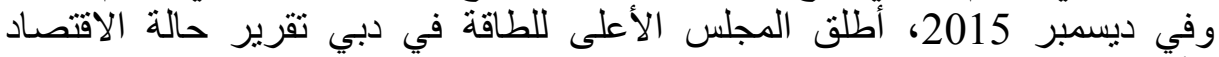

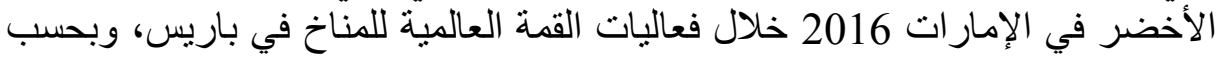

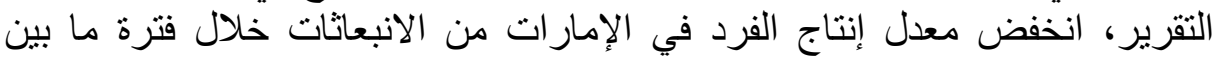

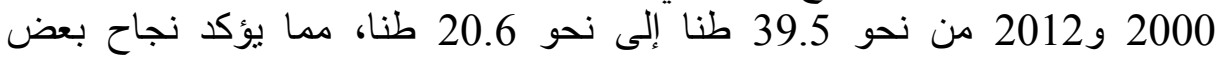

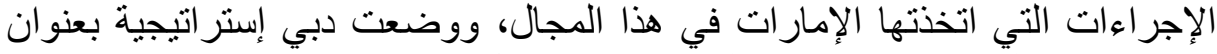

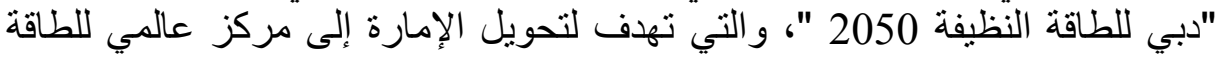

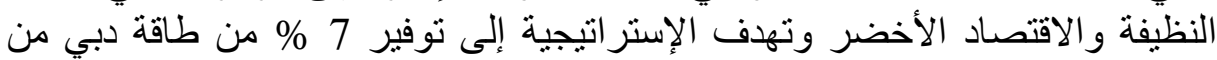

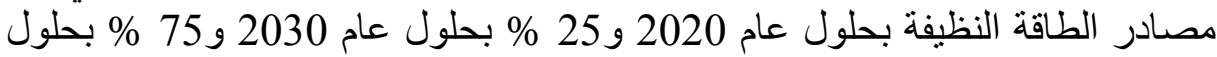
عام 2050، كما تسعى الإستر اتيجية إلى خفض الطلب على على الكهرباء و المياه بنسبة 30 الكالب

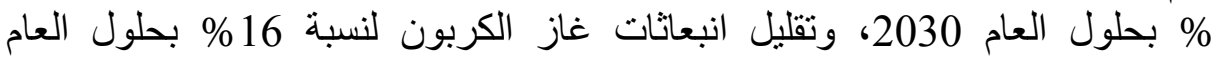

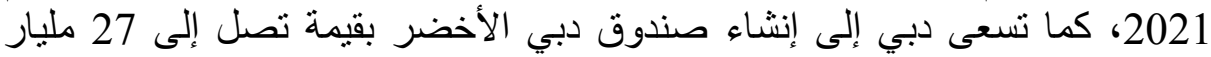
دولار لتحفيز الاستثمار ات الخضر اءه والنمو الأخضر. (34)

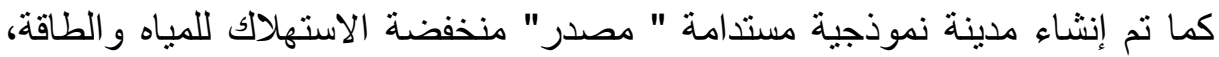

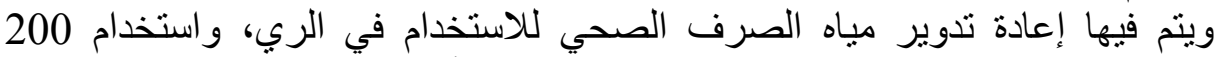

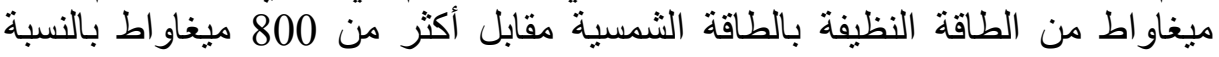
لمدينة تقليدية بنفس الحجم، و استهلاك 8000 متر مكعب من مياه التحلية يوميا مقارنة

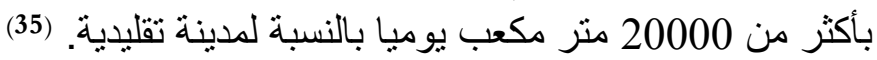




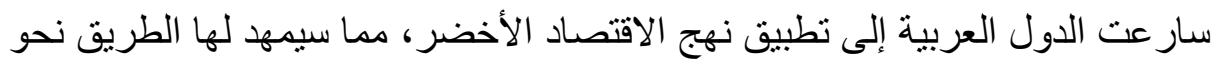

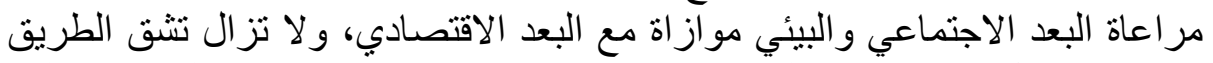

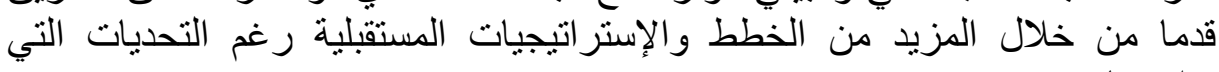

أولا: نتائج الدراسة.

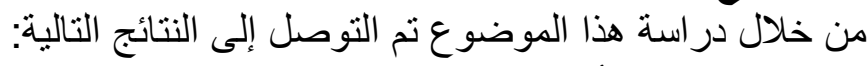

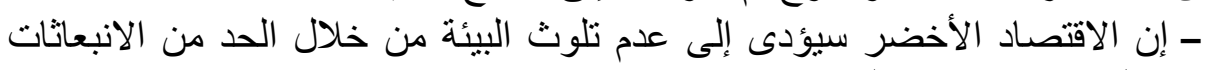
الكربونية وتدوير النفايات؛

$$
\text { - يخلق الاقتصاد الأخضر المزيد من فرص العمل؛ }
$$

- يعزز الاقتصاد الأخضر من منهج التنمية المستدامة.

ثنانيا: توصيات الدراسة

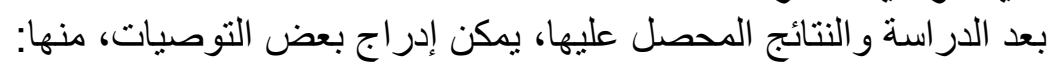

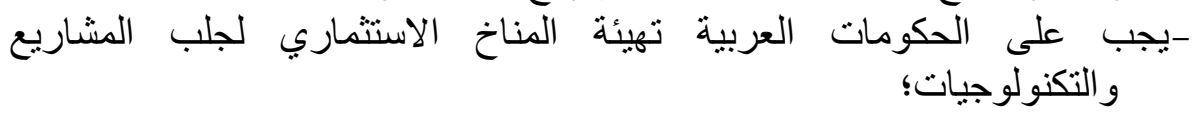

- ضرورة تطوير نماذج وأساليب اقتصادية إقليمية لتقدير كلفة التحول إلى الاقتصاد الأخضر؛

-ضرورة توفر ظروف تمكينية من خلال تكييف الإطار التشريعي وتفعيله بالنظر لتحديات الاقتصاد الأخضر؛

- تطوير الآليات الإقتصادية والمالية الملائمة لدعم تتفيذ البرامج ذات الأولوية مثل النجاعة الطاقية و إنشاء فروع تدوير الأهة النفايات؛

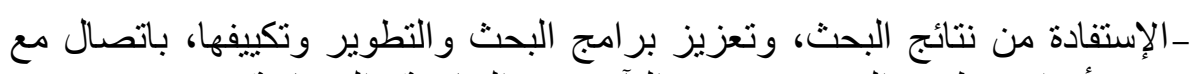
أهداف تطوير الفروع وتعزيز التازرر بين الجامعة واليز والصناعة؛

$$
\text { - تطوير نظام الضر ائب البيئية؛ }
$$

- تعزيز آليات دعم المؤسسات الصغيرة والمتوسطة جدا والتي تعتبر كمحرك لعجلة

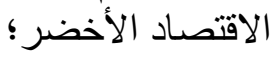

- إعداد دليل للمهن الخضر اء و إنشاء آلية لليقظة خاصة بالحاجات في هذا المجال؛ -ضرورة تطوير مؤشرات موثوقة خاصة بالمنطقة لقياس التقدم المحرز في أنشطة

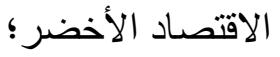

- إنشاء لجنة إقليمية لتبادل الخبرات وتبادل المعلومات عن الاقتصاد الأخضر. 
(1)- برنامج الأمم المتحدة للبيئة، نحو اقتصاد أخضر مسارات إلى التتمية المستدامة

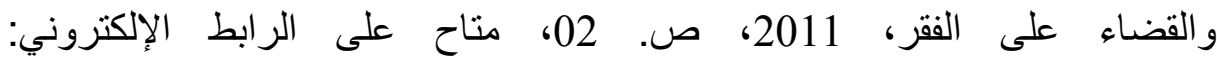
www.unep.org/greeneconomy

(2)- محمد عبد القادر الفقي، الاقتصاد الأخضر، المنظمة الإقليمية لحماية البيئة البحرية، 2014، ص. صلـ 03، متاح على الر ابط الإلكتروني: http://www.ropme.org/Uploads/Books/green\%20economy\%20booklet.p (3)- نفس المرجع السابق، ص. 06.

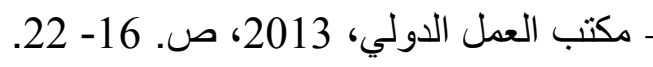

(5)- برنامج الأمم المتحدة للبيئة، المسائل المتعلقة بالسياسات والإدارة البيئية الدولية:

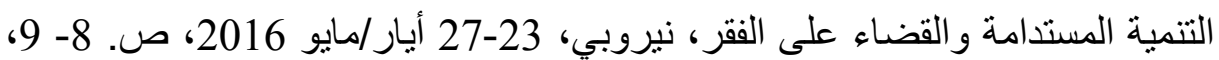
متاح https://digitallibrary.un.org/record/704510/files/A_66_25-AR.pdf (6)- برنامج الأمم المتحدة للبيئة، قضايا السياسات العامة: قضايا السياسات العامة

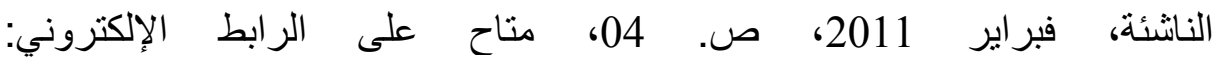
https://wedocs.unep.org/.../K1170132_a-GC-26-17-Add_2.pdf

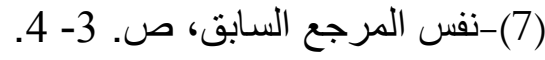

(8)- برنامج الأمم المتحدة للبيئة، نحو اقتصاد اخضر - مسار ات إن إلى التتمية المستدامة

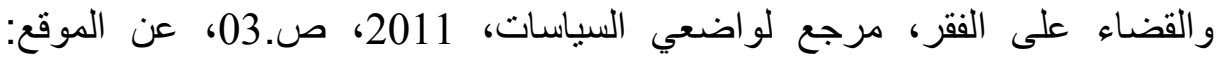
www.unep.org/greeneconomy (9)- برنامج الأمم المتحدة للبيئة، المسائل المتعلقة بالسياسات والإدارة البيئية الدولية:

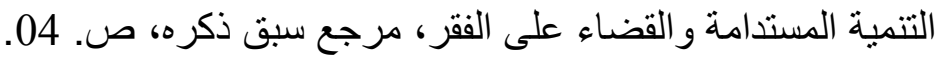
(10)-نفس المرجع السابق، ص. 8.

(11)- برنامج الأمم المتحدة للبيئة، قضايا السياسات العامة: قضايا السياسات العامة

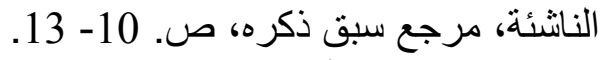
(12)- برنامج الأمم المتحدة للبيئة، نحو اقتصاد أخضر- مسارات إلى إلى التنمية

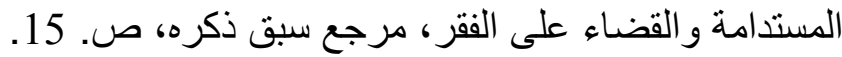

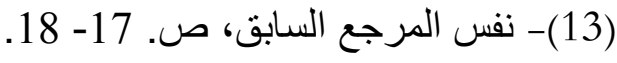

$$
\begin{aligned}
& \text { (14)- نفس المرجع السابق، ص. } 05 \text { (15) } \\
& \text { (15)- نفس المرجع السابق، ص. } 05 .
\end{aligned}
$$

(16)- برنامج الأمم المتحدة للبيئة، قضايا السياسات العامة: فضانة قضايا السياسات العامة

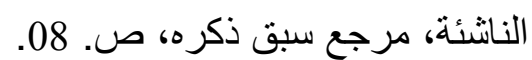

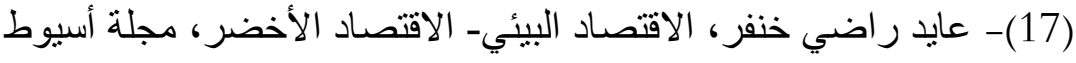

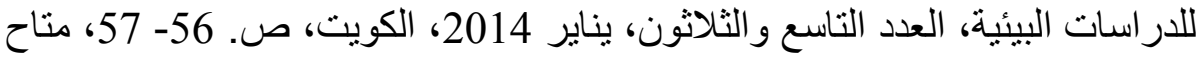

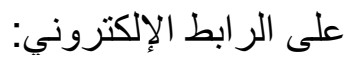
www.aun.edu.eg/arabic/society/pdf/ajoes39_article5.pdf (18)-نفس المرجع السابق، ص. 56- 57. 
(19)-برنامج الأمم المتحدة، نحو اقتصاد أخضر - مسارات إلى التنمية المستدامة

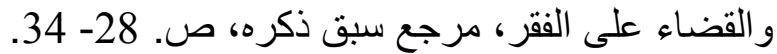
(20)- برنامج الأمم المتحدة للبيئة، المسائل المتعلقة بالسياسات وركات الإدارة البيئية الدولية:

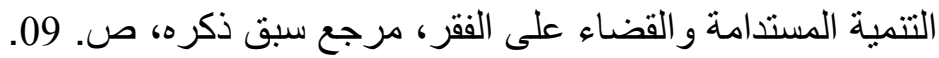

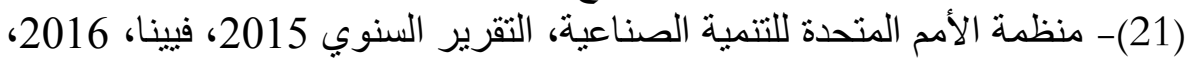

$$
\text { ص. 68، متاح على الرابط الإلكتروني: }
$$

https://www.unido.org/sites/default/files/2016.../1602032_UNIDO_AR_A_ebook_2.pdf (22)- برنامج الأمم المتحدة للبيئة، نحو اقتصاد أخضر - مسارات إلى التنمية

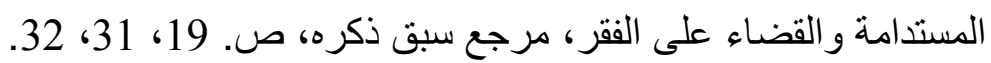

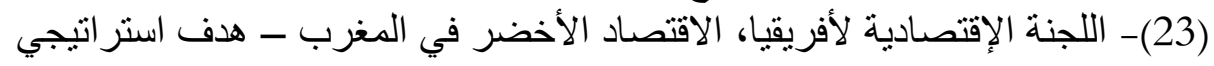
يستدعي تحفيز الثر اكات وتحسين اتساق السياسات والمبادرات، مكتب شمال أفريقيا، ص. 2، 7- 11، 11، مناح على الرابط الإلكتروني: https://www.uneca.org/sites/default/files/uploadeddocuments/SROs/NA/AHEGM-ISDGE/egm_ge-_morocco_ar.pdf (24)- المجلس الاقتصادي والاجتماعي، الاقتصاد الأخضر - فرص لخلق الثروة

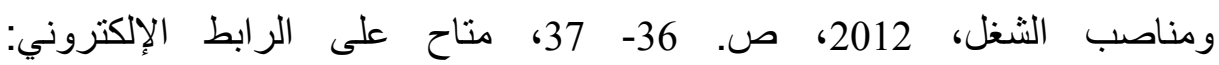
www.ces.ma (25)- القانون رقم 99.12 بمثابة ميثاق وطني للبيئة و التنمية المستدامة، منشور

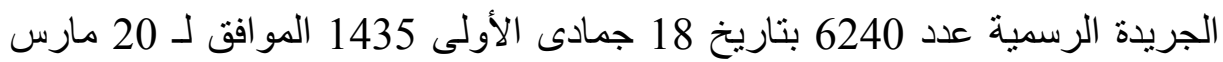

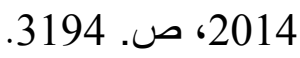
(26)-المادة رقم 2 من المرسوم رقم 922-99-20، الصـادر في 13 يناير 2000،

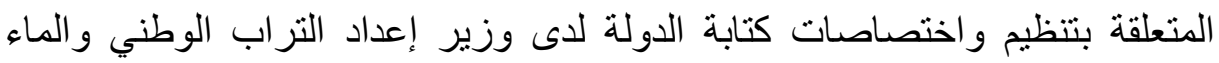

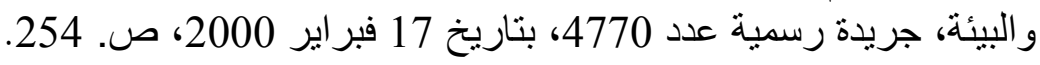
(28)- نفس المرجع السابق، المادة رقم 3. (28)- المادة رقم 3 من المرسوم رقم 758-14-27، صادر في في 30 صفر 1436

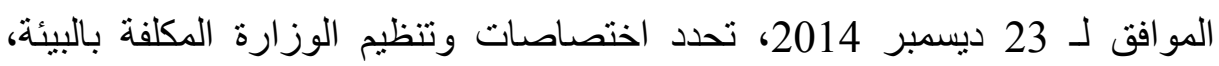

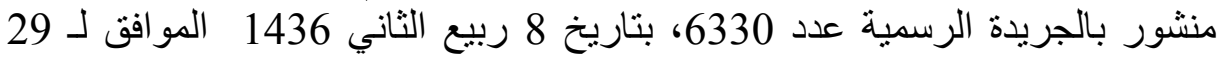

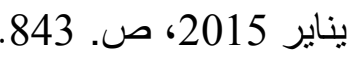
(29)- المادة 7 من نفس المرسوم. (30)-القانون رقم 47.09 المتعلق بالنجاعة الطاقية، الصادر بتاريخ 01 ذبي ذي القعدة

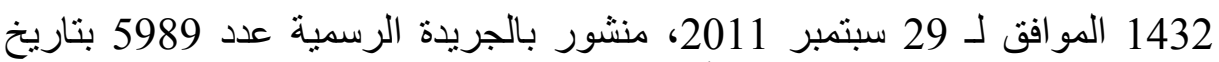

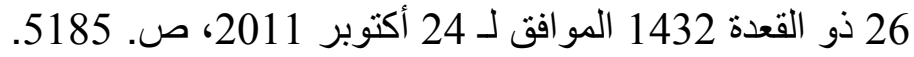
(31)- السياسة الحكومية في مجال الفلاحة و التنمية الريفية والصيد البحري، وزئ وزارة

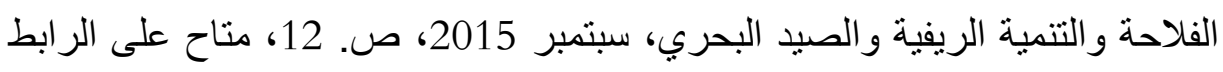
http://www.premier- الإلكتروني: ministre.gov.dz/ressources/front/files/pdf/politiques/agriculture-peche- 
(32)- اللجنة الإقتصادية لأفريقيا، الاقتصاد الأخضر في الجزائر - فرصة لتنويع الإنتاج الوطني وتحفيزه، مكتب شمال أفريقيا، ص ص. صالإنـ 1-2، 12-12، مناح على

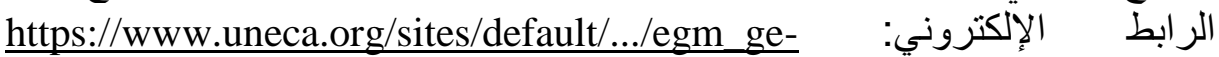
algeria_ar.pdf (33)-شركة إنفجن للاستشار ات، برنامج الأمم المتحدة للبيئة، نحو اقتصاد أخضر في http://inform.gov.jo/ar- الأردن، أغسطس 2011، متاح على الرابط الإلكتروني (34)- إتحاد المصارف العربية -إدارة الدراسات والبحوث، آفاق الاقتصاد الأخضر

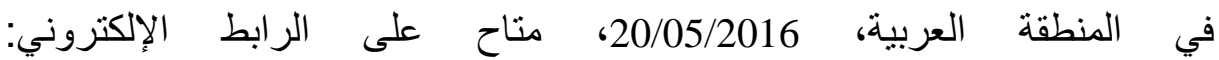
http://www.uabonline.org/ar/research/economic

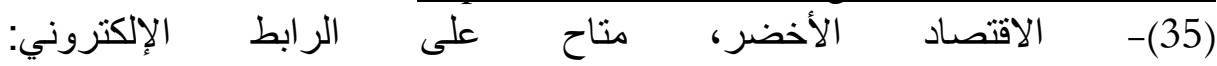
http://www.beatona.net/CMS 